\title{
Dynamical downscaling for regional climate projection in Central Asia based on bias-corrected multiple GCMs
}

\section{Yuan Qiu ( $\nabla$ qiuyuan@tea.ac.cn ) Jinming Feng Institute of Atmospheric Physics Chinese Academy of Sciences \\ Zhongwei Yan \\ Institute of Atmospheric Physics Chinese Academy of Sciences \\ Jun Wang \\ Institute of Atmospheric Physics Chinese Academy of Sciences}

Institute of Atmospheric Physics Chinese Academy of Sciences https://orcid.org/0000-0002-4531-077X

\section{Research Article}

Keywords: regional climate projection, dynamical downscaling, bias correction, Central Asia, near-term future

Posted Date: March 11th, 2021

DOl: https://doi.org/10.21203/rs.3.rs-276894/v1

License: (1) (1) This work is licensed under a Creative Commons Attribution 4.0 International License. Read Full License

Version of Record: A version of this preprint was published at Climate Dynamics on August 18th, 2021. See the published version at https://doi.org/10.1007/s00382-021-05934-2. 


\section{Abstract}

Central Asia (CA) is among the most vulnerable regions to climate change due to the fragile ecosystems, frequent natural hazards, strained water resources, and accelerated glacier melting, which underscores the need to achieve robust projection of regional climate change. In this study, we applied three bias-corrected global climate models (GCMs) to conduct $9 \mathrm{~km}$-resolution regional climate simulations in CA for the present (1986-2005) and future (2031-2050) periods. Dynamical downscaling based on multiple bias-corrected GCM outputs obtains numerous added values not only in reproducing the historical climate but also in projecting the climate changes in CA, in comparison to the original GCMs. The regional climate model (RCM) simulations indicate significant warming over CA in the near-term future, with the regional mean increase of annual daily mean temperature (Tmean) in a range of $1.63-2.01^{\circ} \mathrm{C}$, relative to the present period. This increase is expected to be higher north of $\sim 45^{\circ} \mathrm{N}$ in each season except summer and the high-elevation areas have a weaker warming signal than the plains through the year. The season with the largest warming rate is not consistent among the RCM simulations, highlighting the necessity of using multiple GCMs as the boundary conditions to give a range of the projected climate changes. A slight increase in annual precipitation is consistently projected in most plain areas, although the changes over few areas are statistically significant. The climate projections presented here serve as a robust scientific basis for assessment of future risk from climate change in CA.

\section{Introduction}

Central Asia (hereafter CA), ranging from the Caspian Sea in the west to China in the east and from Russia in the north to Afghanistan and Iran in the south, is consisted of Kazakhstan, Kyrgyzstan, Tajikistan, Turkmenistan, and Uzbekistan, with an area of about 4,000,000 km² (Fig. 1a). There are Tien Shan and Pamir mountain ranges in the southeast, the vast grassy steppes of Kazakhstan in the north, and the Kyzylkum and Karakum desert in the south. Located within the Eurasia continent and far from the oceans, this region has arid and semiarid climate with cold winter and hot summer, sparse precipitation, strong potential evaporation, and large annual and daily temperature ranges.

CA has experienced a significant warming $\left(0.16^{\circ} \mathrm{C}\right.$ per decade) during the past century $(1901-2003$, Chen et al., 2009), with an accelerating warming rate $\left(0.36-0.42^{\circ} \mathrm{C}\right.$ per decade) in the past $\sim 30$ years $(1979-2011$, Hu et al., 2014), which is detected to be mainly contributed by the anthropogenic forcing, particularly the greenhouse gases forcing (Peng et al., 2019). Meanwhile, a significant increase in annual precipitation was observed in CA (Chen et al., 2011).

The warming and wetting trend in CA has increased both exposure and vulnerabilities to natural hazards, such as heatwaves (Yu et al., 2020;Wang et al., 2020a), landsides, floods, and droughts (Thurman, 2011). The World Bank reported that natural disasters lead, on average, to an astounding \$10 billion in estimated economic losses every year (Burunciuc, 2020). The cost is very likely to rise in the future. Water is the most precious resource in CA and its use is the most conflict-prone (Frenken, 2013). A warming future can aggravate the tensions concerning water allocation between upstream and downstream areas in this region. Climate change has exacerbated the glacier melting in the Tien Shan (Narama et al., 2010). Although in the first instance shrinking glaciers supply ample quantities of water in the form of increased glacier runoff, 
reduced glacier volume will ultimately result in a decrease in glacier and total runoff and eventually transform glacial-nival runoff regions in the Tien Shan into nival-pluvial regions (Sorg et al., 2012). The local ecosystems are very sensitive to temperature and precipitation changes (Zhang et al., 2016;Seddon et al., 2016;Gessner et al., 2013), which are anticipated to vary dramatically in the coming decades.

Due to the severe climate changes, frequent natural hazards, strained water resources, accelerated glacier melting and fragile ecosystems in CA, it is imperative to project the regional climate change based on emission scenarios for application to vulnerability, impacts, and adaption assessments. Some efforts have been devoted on climate change projections in CA with both global climate models (GCMs) and regional climate models (RCMs). The GCM simulations largely agree on a regionwide precipitation increase in CA by the end of this century (Huang et al., 2014; Jiang et al., 2020a). The RCM simulations by Mannig et al. (2013) and Ozturk et al. (2017) consistently show notable warming in the cold season in northern CA. A recent study with the use of RCM found hot days and extreme drought events will increase significantly over CA in the future (Zhu et al., 2020).

To date, the studies about climate change projections in CA are still limited relative to its surrounding areas, like East Asia, South Asia and the Mediterranean region (Darmaraki et al., 2019;Gao et al., 2006;Kumar and Dimri, 2018;Niu et al., 2018;Supari et al., 2020;Zittis et al., 2019;Zou and Zhou, 2016, 2017). Most of the previous RCM simulations used a single GCM as the boundary conditions (Mannig et al., 2013;Zhu et al., 2020), which harbor high uncertainties in the projected climate changes. The present authors carried out a study that involving the dynamical downscaling of three different GCMs (CCSM4, HadGEM2-ES, and MPIESM-MR, Table 1) for the CA region with a horizontal resolution of $9 \mathrm{~km}$, for the first time. The future (reference or present) simulation period is 2031-2050 (1986-2005) under Representative Concentration Pathway (RCP) 4.5. As reported in the $1.5^{\circ} \mathrm{C}$ special report of the Intergovernmental Panel on Climate Chane (IPCC), we are on track to exceed $1.5^{\circ} \mathrm{C}$ warming between 2030 and 2052 based on the current warming rate, and hence the near-term future projection becomes more critical to human development than that for the end of this century. Nevertheless, climate changes in $\mathrm{CA}$ in the near-term future have not been investigated yet. 
Table 1

Information about the datasets used in the study

\begin{tabular}{|lllll|}
\hline Model & Run & $\begin{array}{l}\text { Spatial } \\
\text { Resolution }\end{array}$ & $\begin{array}{l}\text { Temporal } \\
\text { Resolution }\end{array}$ & Variables \\
\hline CCSM4 & $\begin{array}{l}\text { b40. } \\
\text { [20th\RCP4.5].track1.1deg.012.cam2.h4 }\end{array}$ & $0.9^{\circ} \times 1.3^{\circ}$ & 6-hourly & Full \\
\hline $\begin{array}{l}\text { HadGEM2- } \\
\text { ES }\end{array}$ & r1i1p1 & $1.3^{\circ} \times 1.9^{\circ}$ & 6 -hourly & Full \\
\hline $\begin{array}{l}\text { MPI-ESM- } \\
\text { MR }\end{array}$ & r1i1p1 & $1.9^{\circ} \times 1.9^{\circ}$ & 6 -hourly & Full \\
\hline CRU TS v4 & - & $0.5^{\circ} \times 0.5^{\circ}$ & monthly & Tmean/Tmax/Tmin \\
\hline CPC & - & $0.5^{\circ} \times 0.5^{\circ}$ & daily & Tmean $/$ Tmax/Tmin \\
\hline ERA5 & - & $0.25^{\circ} \times$ & daily & Precipitation \\
\hline
\end{tabular}

All GCMs suffer from some kinds of bias, which can be problematic for the downscaling applications especially dealing with extreme weather events (Done et al., 2015;Ehret et al., 2012;Liang et al., 2008;Xu and Yang, 2012). Thus, a bias-correction technique (Bruyère et al., 2014) is applied to correct the climatology of the GCMs used in this study to reduce their biases before the regional modeling. Three questions need to be considered:

- What improvements or added values do the bias-correction technique and the dynamical downscaling method obtain respect to the driving GCMs?

- What are the basic features of the projected climate changes across the RCM simulations?

- How does the use of the RCM driven by the bias-corrected GCMs modulate the climate change signals in the original global models?

The present paper is, therefore, to evaluate the high-resolution climatology of the downscaled outputs from three GCMs as well as the GCM outputs; and to demonstrate the projected climate changes in the RCM simulations with respect to the GCM ones. The remainder of this paper is organized as follows: Sect. 2 describes the data and methods. Model evaluation and projected changes are in Sect. 3. Discussion and conclusion are in Sect. 4 and 5, respectively.

\section{Data And Methods}

\subsection{Model description and configuration}

In this study, the WRF model is used in a nested domain (Fig. 1b). The outer domain with a resolution of $27 \mathrm{~km} \times 27 \mathrm{~km}$ covers a large Central Asia region (much larger than the CA region as defined and focused in 
this study), like in the CORDEX project (https://cordex.org/). The inner domain has a high resolution of $9 \mathrm{~km} \times$ $9 \mathrm{~km}$, covering the CA region. The model has 33 levels in the vertical direction with its top fixed at $50 \mathrm{hPa}$. The physical schemes in the regional model are set based on our previous work about the sensitivity study of different physical parameterizations of the WRF model in simulating the local climate in CA (Wang et al., 2020b). They comprise the Thompson aerosol-aware microphysics scheme (Thompson and Eidhammer, 2014), the New Tiedtke cumulus scheme (Zhang et al., 2011), the Yonsei University planetary boundary layer scheme (Hong et al., 2006), the RRTMG shortwave and longwave schemes (lacono et al., 2008), and the Noah-MP (multi-physics) land surface model (Niu et al., 2011). Spectral nudging with a weak coefficient of 3 $\times 10^{-5}$ is applied in the outer domain (not in the inner one), which relaxes the model simulations of wind, temperature, and moisture toward the driving conditions, and prevents possible model drift over the long-term integration. Despite greenhouse gases and solar constants, the WRF model is modified to consider other external forcing, such as aerosols, volcanoes, and ozone, so as to make its inner external forcing consistent with the driving GCMs. We evaluated the modified WRF model in East Asia and found that using full external forcing improves the regional simulation there (Luo et al., 2020).

CCSM4 (referred as CCSM), HadGEM2-ES (referred as Had), and MPI-ESM-MR (referred as MPI) from Phase 5 of the Coupled Model Intercomparison Project (CMIP5) are selected to drive the WRF model. The RCM simulations are referred as CCSM-WRF, Had-WRF, and MPI-WRF, respectively. The reference (or present) simulations are from 1986 to 2005 and the future runs are between 2031 and 2050 under a moderate carbon emission scenario RCP 4.5, which is arguably the most policy-relevant scenario as the Nationally Determined Contributions (NDCs) greenhouse gas emissions framework would produce similar temperatures trajectories (Gabriel and Kimon, 2015).

Since all GCMs suffer from some forms of bias that may propagate down to the RCM outputs, the biascorrection technique developed by Bruyère et al. (2014) is applied to correct the climatology of the GCMs used in this study. It blends a 25-year (1981-2005) mean annual cycle from the ERA-Interim Reanalysis data (ERAl, Dee et al., 2011) with GCM-produced 6-hourly perturbation term to produce initial and lateral boundary conditions for nested RCMs, showing an improvement in simulating Atlantic tropical cyclones and North American summer precipitation and temperature. Formulas are as follows:

$$
G C M=G \bar{C} M+G C M
$$

1

$$
E R A I=\stackrel{-}{E R A I+E R A I}
$$

2

$$
G C M_{R}=\bar{E} \bar{R} A I+G C M^{\prime}
$$

3

where overbar terms are the mean annual cycle, primed terms are perturbation from the mean annual cycle, and $G C M_{R}$ is the revised (bias-corrected) GCM outputs at 6-hourly interval. Note that the bias-corrected 
CCSM4 outputs are available on the Research Data Archive (RDA) of University Corporation for Atmospheric Research (UCAR,https://rda.ucar.edu/datasets/ds316.1/\#!access).

\subsection{Climate subregions}

Various types of terrain and altitude range from 0 to $7500 \mathrm{~m}$ above sea level, lead to diverse climates in CA, which underscores the need to do model evaluation and assess the projected climate changes on sub-regions of similar or consistent climate. With the regionalization method used in our previous study (Qiu et al., 2017), the $\mathrm{CA}$ region is divided into four climate sub-regions, each of which is coherent in the seasonal circulation pattern in precipitation. They are northern CA (NCA), middle CA (MCA), southern CA (SCA), and the mountainous areas (MT) (Fig. 1c). From NCA to SCA, there is a transition from the cold temperate zone with wet summer to the subtropical zone with dry summer. The annual precipitation is generally below $400 \mathrm{~mm}$ in the low-elevation areas (NCA, MCA, and SCA); however, it can exceed $1000 \mathrm{~mm}$ in the mountainous areas (MT).

\subsection{Observational data}

Version 4 of the Climatic Research Unit gridded Time Series (CRU TS v4, Harris et al., 2020) is applied to evaluate the simulated daily mean/maximum/minimum temperature (referred as Tmean/Tmax/Tmin) on annual and seasonal scales. CPC (Climate Prediction Center) Global daily temperature from National Oceanic and Atmospheric Administration (NOAA) is used as a supplementary to evaluate the percentiles of the simulated daily temperature. Because the rain-gauge-observation merged in the gridded observations like the $\mathrm{CRU}$ dataset is sparse and unevenly distributed over CA, the new generation reanalysis of European Center for Medium-Range Weather Forecasts (ECMWF), i.e., ERA5 (Hersbach et al., 2020) is used for precipitation estimation, which has high accuracy in revealing the precipitable water vapor and detecting precipitation events over CA and its surrounding areas (Jiang et al., 2019;Jiang et al., 2020b). Before the evaluation, all the observational data are bilinearly interpolated to the WRF model grids.

\section{Results}

\subsection{Model evaluation}

\subsubsection{Surface air temperature}

The observed annual Tmean varies clearly with latitude (Fig. 2a). This is well simulated by the GCMs (CCSM, Had, and MPI) and RCMs (CCSM-WRF, Had-WRF, and MPI-WRF, Fig. S1). However, the gradient along latitude in the GCMs is less than that of the observation and RCMs. In addition, the RCMs with finer resolution bring more details in describing the cold conditions in the mountainous areas than the global models. The spatial correlation coefficients (SCCs) of the RCMs are 0.96-0.97 (Table 2), larger than those of GCMs (0.92). 
Table 2

Spatial correlation coefficient (SCC), mean error $\left(\mathrm{ME},{ }^{\circ} \mathrm{C}\right)$, and mean absolute error $\left(\mathrm{MAE},{ }^{\circ} \mathrm{C}\right)$ of the simulated annual and seasonal Tmean over Central Asia relative to the observations.

\begin{tabular}{|llllllll|}
\hline & & CCSM & CCSM-WRF & Had & Had-WRF & MPI & MPI-WRF \\
\hline ANN & SCC & 0.92 & 0.97 & 0.92 & 0.96 & 0.92 & 0.96 \\
\hline & ME & 2.37 & 0.21 & -0.74 & 0.93 & 2.60 & 0.69 \\
\hline & MAE & 2.82 & 1.01 & 1.43 & 1.46 & 2.92 & 1.27 \\
\hline DJF & SCC & 0.86 & 0.95 & 0.89 & 0.95 & 0.93 & 0.96 \\
& ME & 1.56 & -2.06 & -2.58 & -0.71 & 4.12 & -0.31 \\
\hline \multirow{2}{*}{ MAM } & MAE & 2.84 & 2.61 & 3.35 & 1.73 & 4.35 & 1.42 \\
& SCC & 0.91 & 0.95 & 0.90 & 0.95 & 0.89 & 0.96 \\
\hline & ME & 1.51 & 1.39 & -1.35 & 1.95 & 2.90 & 1.46 \\
\hline JJA & MAE & 2.35 & 1.99 & 1.87 & 2.50 & 3.31 & 2.00 \\
\hline & SCC & 0.88 & 0.96 & 0.89 & 0.96 & 0.91 & 0.96 \\
\hline & ME & 4.73 & 1.87 & 1.04 & 1.87 & 0.94 & 1.60 \\
\hline SON & MAE & 5.02 & 2.28 & 1.97 & 2.28 & 1.74 & 2.00 \\
\hline & SCC & 0.89 & 0.96 & 0.91 & 0.96 & 0.93 & 0.96 \\
\hline & ME & 1.16 & -0.93 & -0.48 & 0.17 & 2.27 & -0.20 \\
\hline & MAE & 1.90 & 1.41 & 1.38 & 1.18 & 2.56 & 1.11 \\
\hline
\end{tabular}

The bias patterns of annual Tmean are distinct between the GCMs (Fig. 2b, $d$ and f). CCSM and MPI severely overestimate the annual Tmean over the whole region except some parts in the southeast; however, Had has large areas of cold bias. On the contrary, the RCMs have similar bias pattern (Fig. 2c, e, and g). In them, warm biases are found over the low-elevation areas except the northernmost part; in the mountainous areas, annual Tmean is overestimated in the foothills and valleys and underestimated along the mountain ranges and over the plateau.

The probability distribution function (PDF) plot of the bias in annual Tmean (Fig. 3a) reveals that the distribution of CCSM-WRF and MPI-WRF is much closer to the zero line than that of the corresponding GCMs. The mean errors (MEs) and mean absolute errors (MAEs) of annual Tmean over CA are all above $2^{\circ} \mathrm{C}$ in CCSM and MPI, and largely reduced in the downscaled results (Table 2).

CA has cold winter and hot summer (Fig. 4 a and c). It is below $-12^{\circ} \mathrm{C}$ in the north in winter and above $32^{\circ} \mathrm{C}$ in the south in summer. Spring and autumn have similar spatial pattern in Tmean (Fig. $4 \mathrm{~b}$ and d). The three 
different GCM outputs and their downscaled results are all close to the observed seasonal Tmean in CA (Fig. S2 and S3), but the latter have larger SCCs for each season (Table 2).

As found in the annual results, the RCMs also have similar bias patterns of seasonal Tmean (Fig. 4), with large areas of warm (cold) bias over CA during spring and summer (winter). In autumn, the RCM simulated Tmean is slightly warmer (colder) in the southern (northern) part of the low-elevation areas. In addition, warmer foothills and valleys and colder mountain ranges and plateau are detected in the RCMs for each season. However, the bias patterns of seasonal Tmean are distinct between the GCMs (Fig. S4). For instance, warm biases prevail through the year in CCSM and MPI while cold biases occur in all seasons expect summer in Had.

The PDF plots of the bias in seasonal Tmean show that the bias-correction technique and the dynamical downscaling method reduced the biases in the GCMs, especially in winter and summer (Fig. 3b-e). For instance, the ME and MAE of summer Tmean in CCSM are $4.73^{\circ} \mathrm{C}$ and $5.02^{\circ} \mathrm{C}$ respectively, which are reduced by more than half in the downscaled results (Table 2). The PDF plots also indicate that the RCM simulations have smaller biases in autumn than in other seasons. The annual and seasonal Tmax and Tmin are also evaluated and the results are similar to those of Tmean (not shown here).

The 1th, 5th, 10th, 30th, 50th, 70th, 90th, 95th, 99th percentiles of the GCM and RCM simulated Tmax and Tmin averaged over CA and its climate subregions are also compared with the observations (Figs. 5 and 6). Figure 5 reveals that the RCMs have excellent performance in simulating all the percentiles (except the 1th percentile) of Tmax averaged over CA, NCA, and MCA, with the points on or close to the dotted line of $y=x$. They slightly overestimate Tmax in the higher percentiles in the SCA region and largely underestimate Tmax in all the percentiles in the MT region. Figure 6 indicates that the RCMs slightly overestimate (underestimate) Tmin in higher (lower) percentiles in CA and all the subregions except the MT region, generally with $<25 \%$ difference from the observations. In the MT region, all the percentiles of Tmin are colder in the RCMs.

\subsubsection{Precipitation}

Annual precipitation is highly unevenly distributed over CA (Fig. 7a). The deserts in the southwest have the least annual value (<0.5mm/day), followed by the southern $(0.5-1.0 \mathrm{~mm} /$ day) and northern $(1.0-1.5 \mathrm{~mm} / \mathrm{day})$ part of Kazakhstan. Annual precipitation is more than $1.5 \mathrm{~mm}$ /day in the mountainous areas, with the maximum values mainly located in west and central Tajikistan and north Kyrgyzstan. The exception is that the eastern part of the Pamir has scarce precipitation. Compared with the observation, the RCMs have good skills in simulating the spatial pattern of annual precipitation in CA and with a high resolution of $9 \mathrm{~km}$ they even produce more details than the observation $\left(0.25^{\circ} \times 0.25^{\circ}\right)$ in the areas of complex terrain (Fig. S5c, e, and $\mathrm{g}$ ). The low-resolution GCMs are able to simulate the distribution of annual precipitation over the plains while they missed most of the details in the high-elevation areas (Fig. S5b, d, and f), with their SCCs much smaller than those of the RCMs (Table 3). 
Table 3

Spatial correlation coefficient (SCC), mean error (ME, mm/day), and mean absolute error (MAE, mm/day) of the simulated annual and seasonal precipitation over Central Asia relative to the observations.

\begin{tabular}{|llllllll|}
\hline & & CCSM & CCSM-WRF & Had & Had-WRF & MPI & MPI-WRF \\
\hline ANN & SCC & 0.64 & 0.83 & 0.75 & 0.84 & 0.74 & 0.85 \\
\hline & ME & -0.04 & -0.18 & -0.06 & -0.11 & -0.19 & 0.02 \\
\hline DJF & MAE & 0.32 & 0.23 & 0.24 & 0.20 & 0.29 & 0.17 \\
& SCC & 0.48 & 0.85 & 0.64 & 0.86 & 0.76 & 0.86 \\
& ME & 0.24 & -0.06 & -0.12 & -0.03 & -0.02 & 0.07 \\
\hline \multirow{2}{*}{ MAM } & MAE & 0.48 & 0.17 & 0.24 & 0.17 & 0.26 & 0.18 \\
& SCC & 0.75 & 0.85 & 0.79 & 0.86 & 0.76 & 0.87 \\
\hline & ME & -0.11 & -0.20 & 0.11 & -0.08 & -0.26 & 0.05 \\
\hline JJA & MAE & 0.31 & 0.31 & 0.36 & 0.25 & 0.42 & 0.23 \\
\hline & SCC & 0.62 & 0.78 & 0.74 & 0.77 & 0.57 & 0.80 \\
& ME & -0.34 & -0.22 & -0.21 & -0.13 & -0.42 & -0.04 \\
\hline \multirow{2}{*}{ SON } & MAE & 0.42 & 0.33 & 0.36 & 0.34 & 0.47 & 0.30 \\
& SCC & 0.57 & 0.80 & 0.69 & 0.80 & 0.74 & 0.81 \\
& ME & 0.04 & -0.25 & -0.02 & -0.20 & -0.07 & -0.01 \\
& MAE & 0.32 & 0.27 & 0.23 & 0.24 & 0.23 & 0.16 \\
\hline
\end{tabular}

All the GCMs have large negative biases ( $<-1.0 \mathrm{~mm} /$ day) in annual precipitation over most of the mountainous areas and the biases over the plains are relatively small (Fig. 7b, d, and f). The bias-correction technique and dynamical downscaling method significantly reduced the biases of the GCMs over the whole region (Fig. 7c, e, and g), which is also reflected by the PDF plot of the bias (Fig. 8a) in which the curves of the $\mathrm{RCMs}$ are narrower with their peaks closer to the zero line.

Figure 9a-d display the observed precipitation in each season and Fig. 10 shows the mean annual cycle of the observed monthly precipitation averaged over CA and its climate subregions (the grey solid lines). From them, we can see that the NCA region has a typical continental climate with the precipitation mainly concentrated in summer (Fig. 10b) and the SCA region has a Mediterranean climate with the rainfall events mainly occur in late winter and spring (Fig. 10d). The MCA region has a transitional climate between that of the SCA and NCA region (Fig. 10c) and the MT region has the most abundant precipitation (Fig. 10e). In addition, the high-precipitation $(>3.0 \mathrm{~mm} /$ day) areas move eastward along the Tien Shan from winter to summer and almost vanish in autumn (Fig. 9a-d), dominated by the midlatitude westerlies (Bothe et al., 2012). 
The RCMs well simulated precipitation in each season (Fig. S7) and the mean annual cycle in CA and its climate subregions (Fig. 10). For instance, they well reproduce the dry (wet) summer in the southern (northern) part of CA (Fig. S7g, k, and o) and capture the peak of rainfall in March in the SCA region (Fig. 10d). Respect to the driving GCMs, the bias-correction technique and dynamical downscaling method have numerous improvements in simulating precipitation on seasonal and monthly scales, including substantially reducing the seasonal biases (e.g., Fig. 8b and e) and improving the simulation of annual cycles (e.g., Fig. 10b and d). In addition, the downscaled results generally have larger SCCs and smaller MAEs than the GCM outputs for all seasons (Table 3).

The 90th, 95th, and 99th percentiles of the simulated daily precipitation averaged over CA and its climate subregions are compared with the observation to evaluate the performance of the models in simulating precipitation extremes. Figure 11 shows that the accuracy of the RCMs in simulating the 90th and 95th percentiles of daily precipitation is comparable to that of the GCMs in CA and all the subregions except the MT region, with the points intertwined with each other. In the MT region, the 90th and 95th percentiles of the RCMs are more realistic (Fig. 11e). The 99th percentiles are discrete among the GCM/RCM simulations in each region, making it hard to do the comparison on this percentile between the GCMs and their downscaled results.

In Sect. 3.1, the simulated Tmean/Tmax/Tmin and precipitation both in the GCMs and RCMs are compared with the observations on various time scales. To sum up, the high-resolution RCMs driven by multiple biascorrected GCMs are very reliable in simulating the local temperature and precipitation in CA despite some systematic biases and obtain substantial added values respect to the original GCMs, which provides a good base for projecting climate changes in CA.

\subsection{Projected changes}

\subsubsection{Surface air temperature}

Figure 12 shows the projected changes in annual Tmean over CA during the near-term future (2031-2050) relative to the reference period (1986-2005) in the GCMs and RCMs and their ensemble means. Note that the slashed areas in Fig. 12a-c and f-h indicate where the changes passed the significant test at the $95 \%$ confidence level using the two-tailed Student's $t$ test and those in Fig. $12 \mathrm{~d}$ and $\mathrm{i}$ indicate where the signals $(+/-)$ of the projected changes in the GCMs/RCMs are consistent. Meanwhile, a modified coefficient of variance $(\mathrm{CV})$ is defined to assess the uncertainties of the projected changes in the GCMs/RCMs. The formula is as follows:

$$
C V=\frac{\sigma}{|\mu|+C}
$$

4

where $\sigma$ and $\mu$ are the standard deviation and mean of the projected changes on each model grid in the GCMs/RCMs. $|\mu|$ instead of $\mu$ is used to limit $C V \geq 0$. $|\mu|$ is added with a very small constant $C=10^{-3}$ to avoid the denominator is equal to zero. 
All the RCMs (CCSM-WRF, Had-WRF, and MPI-WRF) show significant warming over CA in the near-term future (Fig. 12f-h), with the annual Tmean increase averaged over the entire area by $1.89,2.01$, and $1.63^{\circ} \mathrm{C}$, respectively. And they commonly show the temperature will rise faster north of $\sim 45^{\circ} \mathrm{N}$ and the high-elevation areas have a weaker warming signal than the plains. Based on the ensemble mean (see the red bars in Fig. 13), the NCA (MT) region has the highest (lowest) regional mean increase of annual Tmean by $2.05^{\circ} \mathrm{C}$ $\left(1.56^{\circ} \mathrm{C}\right)$ among the four climate subregions. And the annual Tmean increase is strongest (weakest) in Kazakhstan (Kyrgyzstan) among the five countries in CA.

Comparison of the ensemble mean of the GCMs and RCMs (referred as GCM-Ens and RCM-Ens, Fig. 12d vs 12i) shows that they have similar change patterns in annual Tmean despite some differences. The major differences between them are over the mountainous areas where the GCM-Ens has a strong warming signal $\left(1.8-2.0^{\circ} \mathrm{C}\right)$ in west Tajikistan and west Kyrgyzstan, which is not found in the RCM-Ens. Therefore, the GCMEns has an annual Tmean increase averaged over the MT region $0.19^{\circ} \mathrm{C}$ larger than the RCM-Ens (Fig. 13).

The RCMs also show significant warming over CA in each season except some areas in winter (Fig. 14). They commonly show stronger warming in the northern part of CA in all seasons except summer and the regionwide weak warming in the high-elevation areas through the year. However, they disagree on which season has the highest Tmean increase averaged over CA (Fig. 15). CCSM-WRF indicates that autumn has the strongest warming while Had-WRF and MPI-WRF point to summer and spring, respectively. The CV of the projected changes is larger in winter than in other seasons (Fig. 14q-t), which indicates that the RCMs have larger uncertainties in projecting the changes of temperature in winter. The projected changes in annual and seasonal Tmax/Tmin are also analyzed and the results are similar to those of Tmean (not shown here).

\subsubsection{Precipitation}

The RCMs projected weak changes in annual precipitation over CA in the near-term future and the changes over few areas passed the significance test (Fig. 16f-h). However, they consistently show that the annual precipitation will slightly increase over most of the plains (see the slashed areas in Fig. 16i). The CV is greater than 0.5 over most parts of CA (Fig. 16j), which suggests that the three downscaled results have very large uncertainties in projecting the changes of annual precipitation. Some strong drier/wetter signals are found on seasonal scale (Fig. 17). However, few areas passed the significance test and have the common signals of the changes between the regional simulations for each season.

We compared the projected changes of the seasonal precipitation in the GCM and RCM simulations and found the downscaled results are consistent with the driving GCMs in some RCMs and seasons (e.g., Fig. 17g vs Fig. S10g, Fig. 17I vs Fig. S10I) while the opposite circumstances also exist (e.g., Fig. 17a vs Fig. S10a).

\section{Discussion}

In model evaluation, we found that the three downscaled results have similar bias patterns of annual and seasonal Tmean (e.g., Fig. 2c, e, and g) while the original GCMs are distinct between each other (e.g., Fig. 2b, $\mathrm{d}$, and $\mathrm{f}$ ). The reason is that the biases in the RCM outputs mainly come from the ERA-Interim reanalysis which is the climatology component of the WRF inputs. This finding also suggests the use of state-of-the-art 
reanalysis dataset like ERA5 in the bias correction in the future so as to make the downscaled results more reasonable.

A strong warming signal $\left(1.8-2^{\circ} \mathrm{C}\right)$ is found in the GCMs over the western part of the mountainous areas (Fig. 12d), which is not detected in the RCMs (Fig. 12i) and reported by the previous studies about the temperature changes in this region both during the past and in the future (Hu et al., 2014;Mannig et al., 2013;Ozturk et al., 2017). We suspect that it is a fake signal possibly caused by the inaccurate depicting of the terrain in the low-resolution GCMs. This founding indicates that the use of the RCM brings added values not only in simulating the historical climate but also in projecting climate changes in CA. The possible reason why the elevation-dependent warming (EDW) observed or projected in other mountainous regions (Palazzi et al., 2019;Rangwala et al., 2013;Pepin et al., 2015) is not detected in CA is that the important mechanisms that contribute towards EDW, like snow albedo and surface-based feedbacks, are lacked in the Tien Shan and Pamirs, which needs further studies.

Though the RCMs have similar change patterns of annual Tmean, they disagree on which season has the highest Tmean increase averaged over CA (e.g., Fig. 15), suggesting large uncertainties among the three downscaled results and the necessity of using multiple GCMs as the boundary conditions to provide a range of the projected climate changes.

Contrast to the significant increase in temperature over CA in the near-term future, the projected changes in precipitation is weak over CA with few areas passing the significance test (e.g., Fig. 16f-h). A possible reason is that the natural climate variability still plays a major role in uncertainty in CA for projections of precipitation in the near future.

\section{Conclusion}

In this study, three different GCMs (CCSM4, HadGEM2-ES, and MPI-ESM-MR) from CMIP5 are selected to conduct high-resolution $(9 \mathrm{~km})$ dynamical downscaling over CA with the regional climate model WRF for the near-term future (2031-2050) relative to the reference period of 1986-2005, under the carbon emission scenario of RCP4.5. Before the downscaling, a bias-correction technique is used to correct the climatology of the GCMs.

Firstly, we carefully evaluated the simulated Tmean/Tmax/Tmin and precipitation both in the GCMs and RCMs and found that the high-resolution RCMs are excellent in simulating the local temperature and precipitation in CA despite some systematic biases, and obtain substantial added values respect to the original GCMs. In particular, the downscaled results significantly reduce the biases of the GCMs, reproduce the spatial distribution of the local climatology with higher accuracy and more details, better capture the percentiles of Tmax, Tmin and daily precipitation, and produce more realistic annual cycle of precipitation.

Then, the projected changes of annual and seasonal Tmean/Tmax/Tmin and precipitation are analyzed. All the RCMs (CCSM-WRF, Had-WRF, and MPI-WRF) show significant warming over CA in the near-term future, with the annual Tmean increase averaged over the entire area by $1.89,2.01$, and $1.63^{\circ} \mathrm{C}$, respectively. They commonly show the temperature will rise faster north of $\sim 45^{\circ} \mathrm{N}$ and the high-elevation areas have a weaker 
warming than the plains. However, the three downscaled results point to different season that has the largest Tmean increase averaged over CA. Though the projected changes in precipitation is weak over CA with the changes over few areas passing the significance test, the RCMs commonly shows a slight increase of annual precipitation over most of the plains, with is consistent with the ensemble means of multiple GCMs (Huang et al., 2014; Jiang et al., 2020a). Comparison with the projected changes in the GCM and RCM simulations shows that they have similar change patterns in annual Tmean and precipitation while the seasonal results in some RCMs are not consistent with the corresponding GCMs.

To sum up, the use of the RCM driven by the bias-corrected GCMs achieves a fairly good balance between assuring the high accuracy of the RCM outputs and preserving the climate variances from the original global models. While this paper demonstrates the basic features of the simulated and projected climatology in CA from multi-GCMs-driven RCMs, more analyses of the downscaled results will be beneficial. The simulated changes of the extreme weather events, such as heatwaves, dry spells, and extreme precipitation events, deserves a further study, among many more potential applications to climate change risk assessment for the region.

\section{Declarations}

\section{Acknowledgements}

CPC Global Temperature data provided by the NOAA/OAR/ESRL PSL is available at https://psl.noaa.gov/data/gridded/data.cpc.globaltemp.html. This study was supported by the Strategic Priority Research Program of Chinese Academy of Sciences (Grand No. XDA20020201) and the General Project of the National Natural Science Foundation of China (Grand No. 41875134).

Funding: This study was supported by the Strategic Priority Research Program of Chinese Academy of Sciences (Grand No. XDA20020201) and the General Project of the National Natural Science Foundation of China (Grand No. 41875134).

Conflicts of interest/Competing interests: no conflicts of interests for authors.

Availability of data and material: The downscaled results produced in this study will be available at National Tibetan Plateau/Third Pole Environment Data Center (http://data.tpdc.ac.cn/en/).

Code availability: The code used to correct the climatology of the global climate models is available at https://rda.ucar.edu/datasets/ds316.1/\#!software.

Authors' contributions: All the authors made substantial contributions to the conception or design of the work. Yuan Qiu did the analyses and drafted the work and others revised it.

\section{References}

Bothe, O., Fraedrich, K., and Zhu, X.: Precipitation climate of Central Asia and the large-scale atmospheric circulation, Theoretical and Applied Climatology, 108, 345-354, 10.1007/s00704-011-0537-2, 2012. 
Bruyère, C. L., Done, J. M., Holland, G. J., and Fredrick, S.: Bias corrections of global models for regional climate simulations of high-impact weather, Climate Dynamics, 43, 1847-1856, 10.1007/s00382-013-2011-6, 2014.

Burunciuc, L.: Natural disasters cost Central Asia \$10 billion a year - Are we doing enough to prevent them?, World Bank Blogs, 2020.

Chen, F., Wang, J., Jin, L., Zhang, Q., Li, J., and Chen, J.: Rapid warming in mid-latitude central Asia for the past 100 years, Frontiers of Earth Science in China, 3, 42, 10.1007/s11707-009-0013-9, 2009.

Chen, F., Huang, W., Jin, L., Chen, J., and Wang, J.: Spatiotemporal precipitation variations in the arid Central Asia in the context of global warming, Science China Earth Sciences, 54, 1812-1821, 10.1007/s11430-0114333-8, 2011.

Darmaraki, S., Somot, S., Sevault, F., Nabat, P., Cabos Narvaez, W. D., Cavicchia, L., Djurdjevic, V., Li, L., Sannino, G., and Sein, D. V.: Future evolution of Marine Heatwaves in the Mediterranean Sea, Climate Dynamics, 53, 1371-1392, 10.1007/s00382-019-04661-z, 2019.

Dee, D. P., Uppala, S. M., Simmons, A., Berrisford, P., Poli, P., Kobayashi, S., Andrae, U., Balmaseda, M., Balsamo, G., and Bauer, d. P.: The ERA-Interim reanalysis: Configuration and performance of the data assimilation system, Quarterly Journal of the royal meteorological society, 137, 553-597, 2011.

Done, J. M., Holland, G. J., Bruyère, C. L., Leung, L. R., and Suzuki-Parker, A.: Modeling high-impact weather and climate: lessons from a tropical cyclone perspective, Climatic Change, 129, 381-395, 10.1007/s10584013-0954-6, 2015.

Ehret, U., Zehe, E., Wulfmeyer, V., Warrach-Sagi, K., and Liebert, J.: HESS Opinions "Should we apply bias correction to global and regional climate model data?", Hydrol. Earth Syst. Sci., 16, 3391-3404, 10.5194/hess16-3391-2012, 2012.

Frenken, K.: Irrigation in Central Asia in figures, Food and Agriculture Organization of the United Nations, 2013.

Gabriel, K. A., and Kimon, K.: Analysis of scenarios integrating the INDCs, EUR - Scientific and Technical Research Reports, 2015.

Gao, X., Pal, J. S., and Giorgi, F.: Projected changes in mean and extreme precipitation over the Mediterranean region from a high resolution double nested RCM simulation, Geophysical Research Letters, 33, 10.1029/2005GL024954, 2006.

Gessner, U., Naeimi, V., Klein, I., Kuenzer, C., Klein, D., and Dech, S.: The relationship between precipitation anomalies and satellite-derived vegetation activity in Central Asia, Global Planet Change, 110, 74-87, 10.1016/j.gloplacha.2012.09.007, 2013. 
Harris, I., Osborn, T. J., Jones, P., and Lister, D.: Version 4 of the CRU TS monthly high-resolution gridded multivariate climate dataset, Scientific Data, 7, 109, 10.1038/s41597-020-0453-3, 2020.

Hersbach, H., Bell, B., Berrisford, P., Hirahara, S., Horányi, A., Muñoz-Sabater, J., Nicolas, J., Peubey, C., Radu, R., Schepers, D., Simmons, A., Soci, C., Abdalla, S., Abellan, X., Balsamo, G., Bechtold, P., Biavati, G., Bidlot, J., Bonavita, M., De Chiara, G., Dahlgren, P., Dee, D., Diamantakis, M., Dragani, R., Flemming, J., Forbes, R., Fuentes, M., Geer, A., Haimberger, L., Healy, S., Hogan, R. J., Hólm, E., Janisková, M., Keeley, S., Laloyaux, P., Lopez, P., Lupu, C., Radnoti, G., de Rosnay, P., Rozum, I., Vamborg, F., Villaume, S., and Thépaut, J.-N.: The ERA5 global reanalysis, Quarterly Journal of the Royal Meteorological Society, 146, 1999-2049, https://doi.org/10.1002/qj.3803, 2020.

Hong, S.-Y., Noh, Y., and Dudhia, J.: A New Vertical Diffusion Package with an Explicit Treatment of Entrainment Processes, Monthly Weather Review, 134, 2318-2341, 10.1175/MWR3199.1, 2006.

Hu, Z., Zhang, C., Hu, Q., and Tian, H.: Temperature Changes in Central Asia from 1979 to 2011 Based on Multiple Datasets, 27, 1143-1167, 10.1175/jcli-d-13-00064.1, 2014.

Huang, A., Zhou, Y., Zhang, Y., Huang, D., Zhao, Y., and Wu, H.: Changes of the Annual Precipitation over Central Asia in the Twenty-First Century Projected by Multimodels of CMIP5, Journal of Climate, 27, 66276646, 10.1175/jcli-d-14-00070.1, 2014.

lacono, M. J., Delamere, J. S., Mlawer, E. J., Shephard, M. W., Clough, S. A., and Collins, W. D.: Radiative forcing by long-lived greenhouse gases: Calculations with the AER radiative transfer models, Journal of Geophysical Research: Atmospheres, 113, 10.1029/2008JD009944, 2008.

Jiang, J., Zhou, T., and Zhang, W.: Evaluation of Satellite and Reanalysis Precipitable Water Vapor Data Sets Against Radiosonde Observations in Central Asia, Earth and Space Science, 6, 1129-1148, https://doi.org/10.1029/2019EA000654, 2019.

Jiang, J., Zhou, T., Chen, X., and Zhang, L.: Future changes in precipitation over Central Asia based on CMIP6 projections, Environmental Research Letters, 15, 054009, 10.1088/1748-9326/ab7d03, 2020a.

Jiang, Q., Li, W., Fan, Z., He, X., Sun, W., Chen, S., Wen, J., Gao, J., and Wang, J.: Evaluation of the ERA5 reanalysis precipitation dataset over Chinese Mainland, Journal of Hydrology, 125660 , https://doi.org/10.1016/j.jhydrol.2020.125660, 2020b.

Kumar, D., and Dimri, A. P.: Regional climate projections for Northeast India: an appraisal from CORDEX South Asia experiment, Theoretical and Applied Climatology, 134, 1065-1081, 10.1007/s00704-017-2318-z, 2018.

Liang, X.-Z., Kunkel, K. E., Meehl, G. A., Jones, R. G., and Wang, J. X. L.: Regional climate models downscaling analysis of general circulation models present climate biases propagation into future change projections, Geophysical Research Letters, 35, https://doi.org/10.1029/2007GL032849, 2008.

Luo, M., Feng, J. M., Xu, Z. F., Chen, L., Wang, J., Wang, Y. L., Lin, S., and Zhong, L. H.: Decadal Wintertime Temperature Changes in East Asia During 1958-2001 and the Contributions of Internal Variability and 
External Forcing, Journal of Geophysical Research: Atmospheres, 125, e2019JD031840, 10.1029/2019jd031840, 2020.

Mannig, B., Müller, M., Starke, E., Merkenschlager, C., Mao, W., Zhi, X., Podzun, R., Jacob, D., and Paeth, H.: Dynamical downscaling of climate change in Central Asia, Global and Planetary Change, 110, 26-39, https://doi.org/10.1016/j.gloplacha.2013.05.008, 2013.

Narama, C., Kääb, A., Duishonakunov, M., and Abdrakhmatov, K.: Spatial variability of recent glacier area changes in the Tien Shan Mountains, Central Asia, using Corona ( 1970), Landsat ( 2000), and ALOS ( 2007) satellite data, Global Planet Change, 71, 42-54, 2010.

Niu, G.-Y., Yang, Z.-L., Mitchell, K. E., Chen, F., Ek, M. B., Barlage, M., Kumar, A., Manning, K., Niyogi, D., Rosero, E., Tewari, M., and Xia, Y.: The community Noah land surface model with multiparameterization options (Noah-MP): 1. Model description and evaluation with local-scale measurements, Journal of Geophysical Research: Atmospheres, 116, 10.1029/2010JD015139, 2011.

Niu, X., Wang, S., Tang, J., Lee, D.-K., Gutowski, W., Dairaku, K., McGregor, J., Katzfey, J., Gao, X., Wu, J., Hong, S.-y., Wang, Y., Sasaki, H., and Fu, C.: Ensemble evaluation and projection of climate extremes in China using RMIP models, International Journal of Climatology, 38, 2039-2055, https://doi.org/10.1002/joc.5315, 2018.

Ozturk, T., Turp, M. T., Türkeş, M., and Kurnaz, M. L.: Projected changes in temperature and precipitation climatology of Central Asia CORDEX Region 8 by using RegCM4.3.5, Atmospheric Research, 183, 296-307, https://doi.org/10.1016/j.atmosres.2016.09.008, 2017.

Palazzi, E., Mortarini, L., Terzago, S., and von Hardenberg, J.: Elevation-dependent warming in global climate model simulations at high spatial resolution, Climate Dynamics, 52, 2685-2702, 10.1007/s00382-018-4287-z, 2019.

Peng, D., Zhou, T., Zhang, L., and Zou, L. J. C. D.: Detecting human influence on the temperature changes in Central Asia, 53, 4553-4568, 2019.

Pepin, N., Bradley, R. S., Diaz, H. F., Baraer, M., Caceres, E. B., Forsythe, N., Fowler, H., Greenwood, G., Hashmi, M. Z., Liu, X. D., Miller, J. R., Ning, L., Ohmura, A., Palazzi, E., Rangwala, I., Schöner, W., Severskiy, I., Shahgedanova, M., Wang, M. B., Williamson, S. N., Yang, D. Q., and Mountain Research Initiative, E. D. W. W. G.: Elevation-dependent warming in mountain regions of the world, Nature Climate Change, 5, 424-430, 10.1038/nclimate2563, 2015.

Qiu, Y., Hu, Q., and Zhang, C.: WRF simulation and downscaling of local climate in Central Asia, International Journal of Climatology, 37, 513-528, 10.1002/joc.5018, 2017.

Rangwala, I., Sinsky, E., and Miller, J. R.: Amplified warming projections for high altitude regions of the northern hemisphere mid-latitudes from CMIP5 models, Environmental Research Letters, 8, 024040, 10.1088/1748-9326/8/2/024040, 2013. 
Seddon, A. W., Macias-Fauria, M., Long, P. R., Benz, D., and Willis, K. J.: Sensitivity of global terrestrial ecosystems to climate variability, Nature, 531, 229-232, 2016.

Sorg, A., Bolch, T., Stoffel, M., Solomina, O., and Beniston, M.: Climate change impacts on glaciers and runoff in Tien Shan (Central Asia), Nat Clim Change, 2, 725-731, 2012.

Supari, Tangang, F., Juneng, L., Cruz, F., Chung, J. X., Ngai, S. T., Salimun, E., Mohd, M. S. F., Santisirisomboon, J., Singhruck, P., PhanVan, T., Ngo-Duc, T., Narisma, G., Aldrian, E., Gunawan, D., and Sopaheluwakan, A.: Multimodel projections of precipitation extremes in Southeast Asia based on CORDEX-Southeast Asia simulations, Environmental Research, 184, 109350, https://doi.org/10.1016/j.envres.2020.109350, 2020.

Thompson, G., and Eidhammer, T.: A Study of Aerosol Impacts on Clouds and Precipitation Development in a Large Winter Cyclone, Journal of the Atmospheric Sciences, 71, 3636-3658, 10.1175/jas-d-13-0305.1, 2014.

Thurman, M.: Natural Disaster Risks in Central Asia: A Synthesis, UNDP/BCPR, Regional Disaster Risk Reduction Asvisor, Europe and CIS, 2011.

Wang, J., Chen, Y., Tett, S. F. B., Yan, Z., Zhai, P., Feng, J., and Xia, J.: Anthropogenically-driven increases in the risks of summertime compound hot extremes, Nature Communications, 11, 528, 10.1038/s41467-019-142338, 2020a.

Wang, Y., Feng, J., Luo, M., Wang, J., and Qiu, Y.: Uncertainties in simulating central Asia: Sensitivity to physical parameterizations using Weather Research and Forecasting model, International Journal of Climatology, 40, 5813-5828, https://doi.org/10.1002/joc.6567, 2020b.

Xu, Z., and Yang, Z.-L.: An Improved Dynamical Downscaling Method with GCM Bias Corrections and Its Validation with 30 Years of Climate Simulations, Journal of Climate, 25, 6271-6286, 10.1175/JCLI-D-12$00005.1,2012$.

Yu, S., Yan, Z., Freychet, N., and Li, Z.: Trends in summer heatwaves in central Asia from 1917 to 2016 : Association with large-scale atmospheric circulation patterns, International Journal of Climatology, 40, 115127, https://doi.org/10.1002/joc.6197, 2020.

Zhang, C., Wang, Y., and Hamilton, K.: Improved Representation of Boundary Layer Clouds over the Southeast Pacific in ARW-WRF Using a Modified Tiedtke Cumulus Parameterization Scheme, Monthly Weather Review, 139, 3489-3513, 10.1175/mwr-d-10-05091.1, 2011.

Zhang, C., Lu, D., Chen, X., Zhang, Y., Maisupova, B., and Tao, Y.: The spatiotemporal patterns of vegetation coverage and biomass of the temperate deserts in Central Asia and their relationships with climate controls, Remote Sens Environ, 175, 271-281, 10.1016/j.rse.2016.01.002, 2016.

Zhu, X., Wei, Z., Dong, W., Ji, Z., Wen, X., Zheng, Z., Yan, D., and Chen, D.: Dynamical downscaling simulation and projection for mean and extreme temperature and precipitation over central Asia, Climate Dynamics, $10.1007 /$ s00382-020-05170-0, 2020. 
Zittis, G., Hadjinicolaou, P., Klangidou, M., Proestos, Y., and Lelieveld, J.: A multi-model, multi-scenario, and multi-domain analysis of regional climate projections for the Mediterranean, Regional Environmental Change, 19, 2621-2635, 10.1007/s10113-019-01565-w, 2019.

Zou, L., and Zhou, T.: Future summer precipitation changes over CORDEX-East Asia domain downscaled by a regional ocean-atmosphere coupled model: A comparison to the stand-alone RCM, Journal of Geophysical Research: Atmospheres, 121, 2691-2704, https://doi.org/10.1002/2015JD024519, 2016.

Zou, L., and Zhou, T.: Dynamical downscaling of East Asian winter monsoon changes with a regional oceanatmosphere coupled model, Quarterly Journal of the Royal Meteorological Society, 143, 2245-2259, https://doi.org/10.1002/qj.3082, 2017.

\section{Figures}


(a)

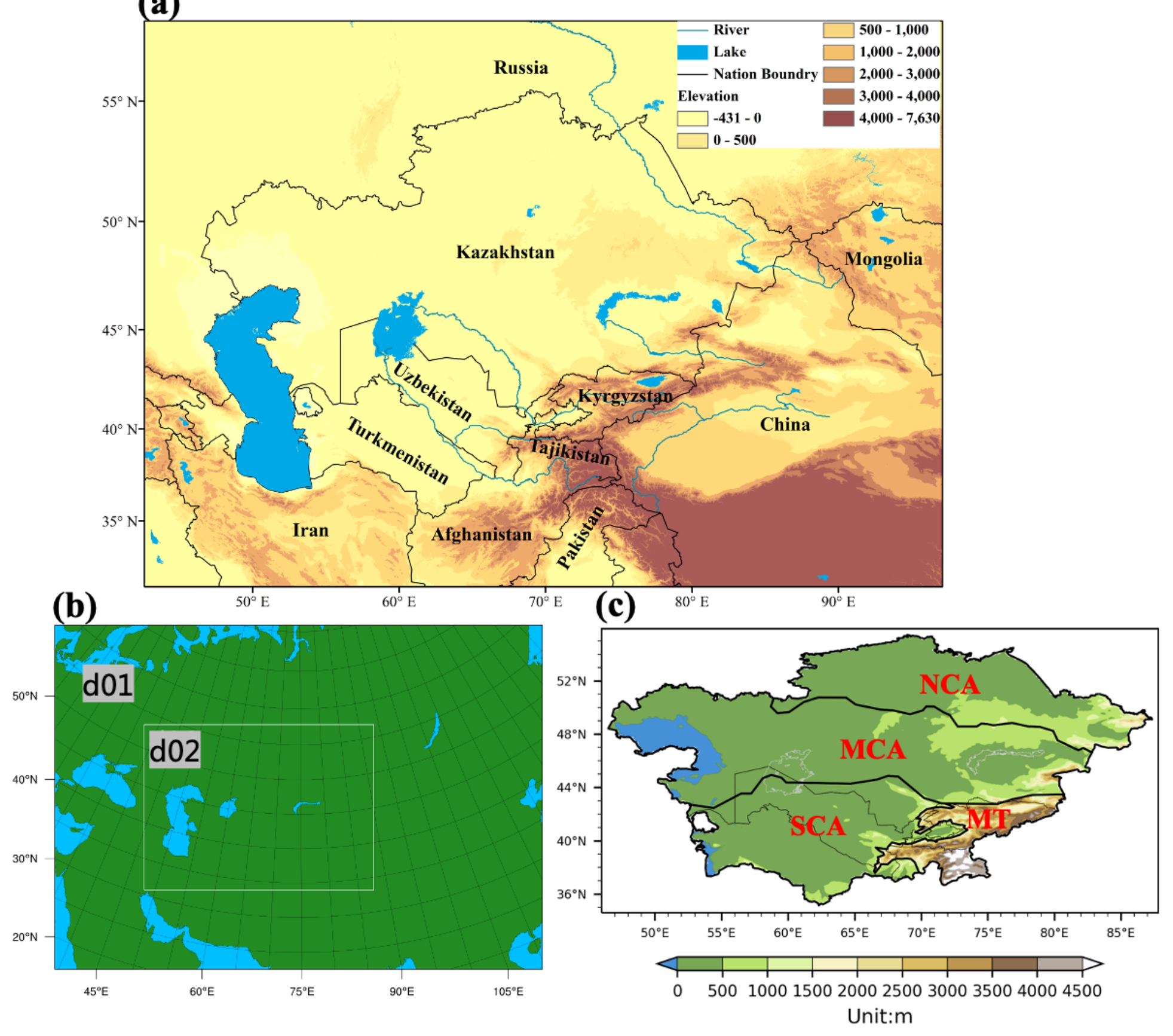

Figure 1

Study area and its surrounding (a), nested domains in the WRF model (b), and climate sub-regions in Central Asia (c). Note: The designations employed and the presentation of the material on this map do not imply the expression of any opinion whatsoever on the part of Research Square concerning the legal status of any country, territory, city or area or of its authorities, or concerning the delimitation of its frontiers or boundaries. This map has been provided by the authors. 
(a)CRU
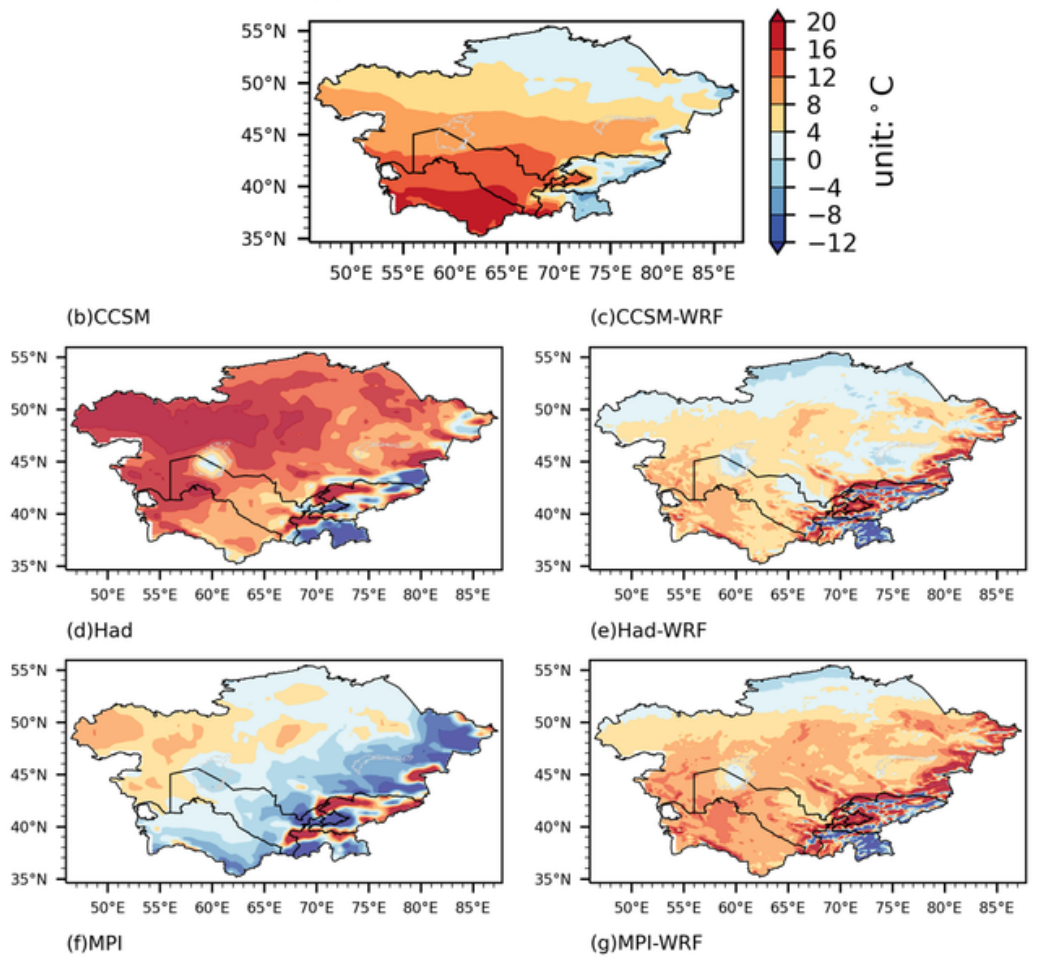

(e)Had-WRF

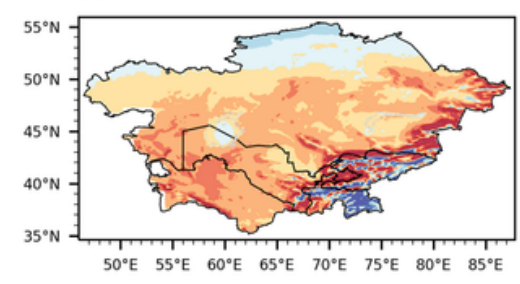

(g)MPI-WRF
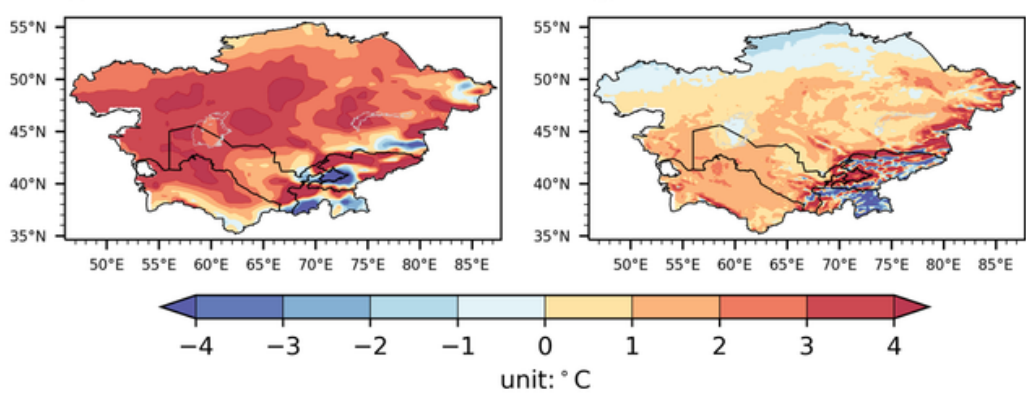

\section{Figure 2}

The observed annual Tmean in Central Asia during the reference period (1986-2005, a) and the biases in the GCM and RCM simulations (b-g). Note: The designations employed and the presentation of the material on this map do not imply the expression of any opinion whatsoever on the part of Research Square concerning the legal status of any country, territory, city or area or of its authorities, or concerning the delimitation of its frontiers or boundaries. This map has been provided by the authors. 

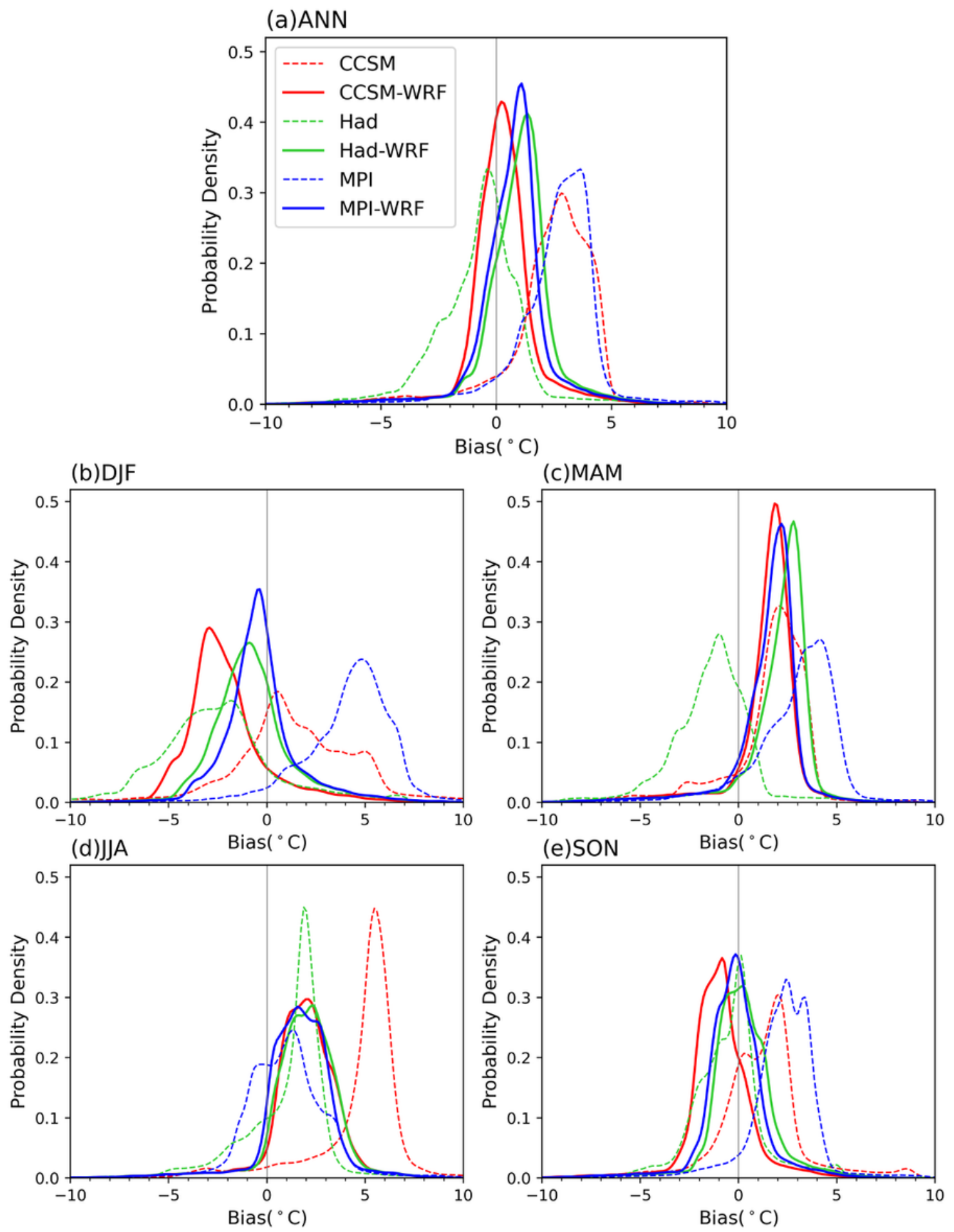

Figure 3

The Probability Density Functions (PDFs) of the bias in the simulated annual and seasonal Tmean over Central Asia during the reference period (1986-2005). 

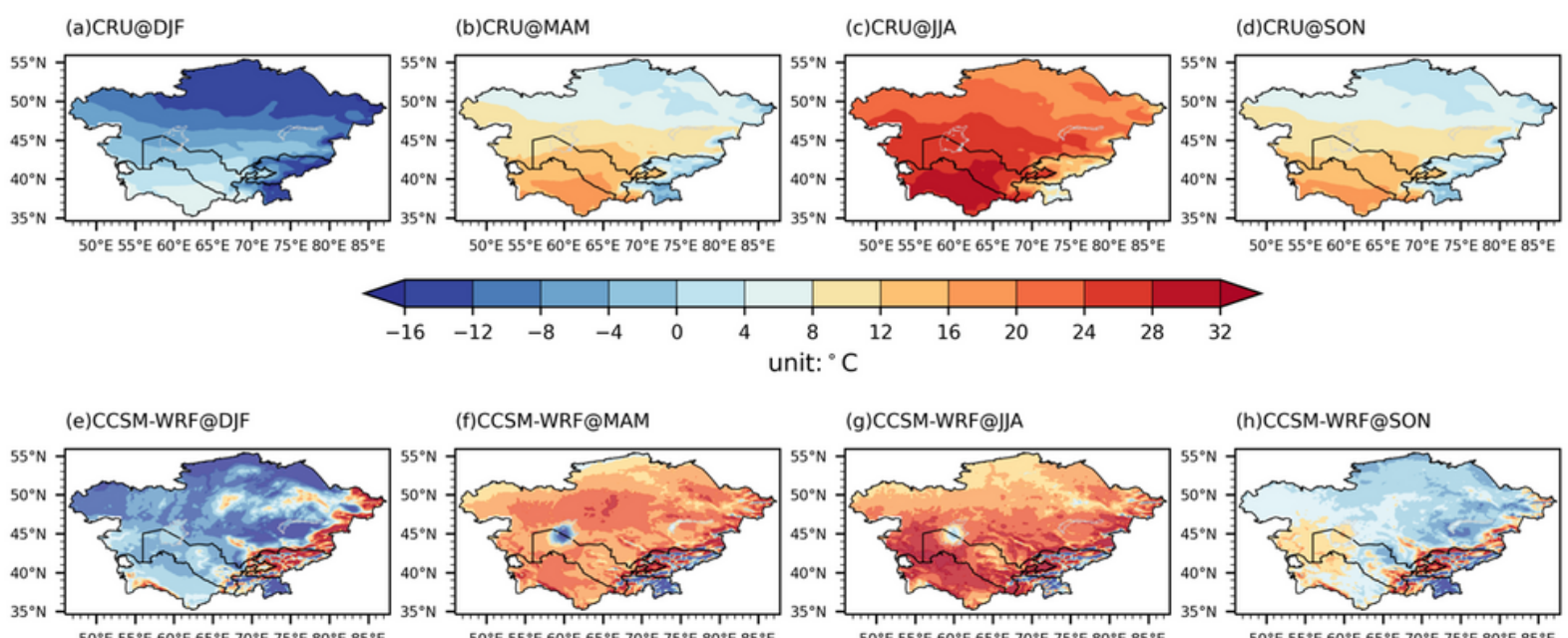

(h)CCSM-WRF@SON

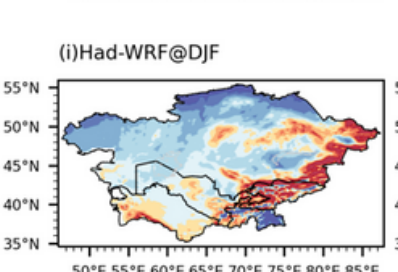

(j)Had-WRF@MAM

(k)Had-WRF@JJA
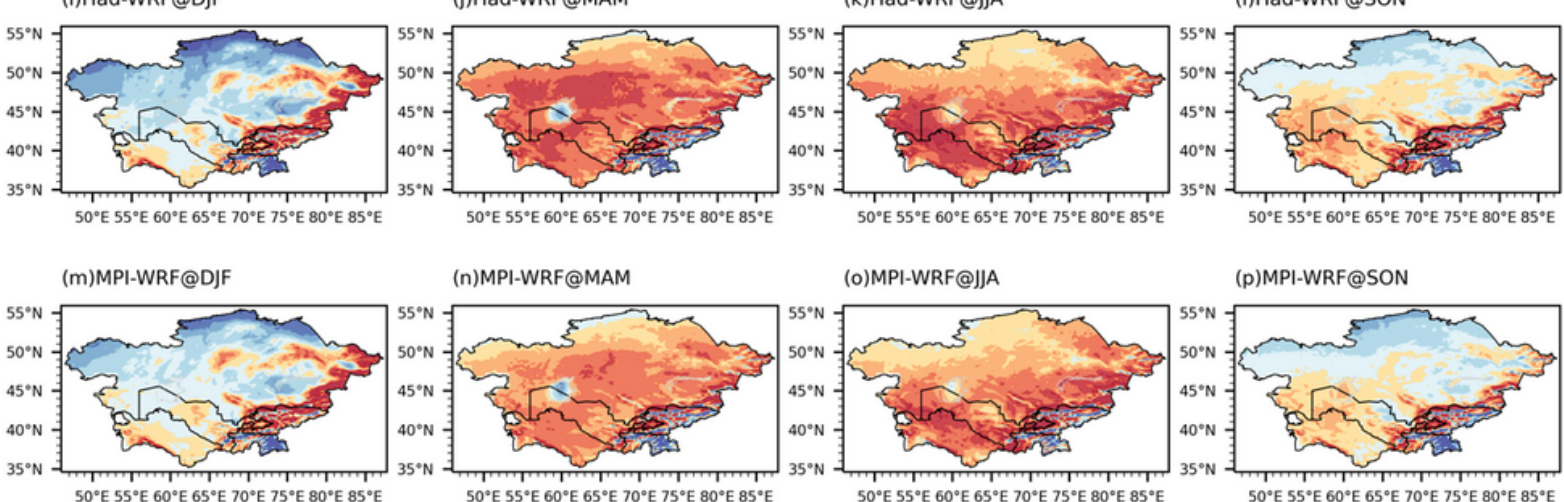

(p)MPI-WRF@SON
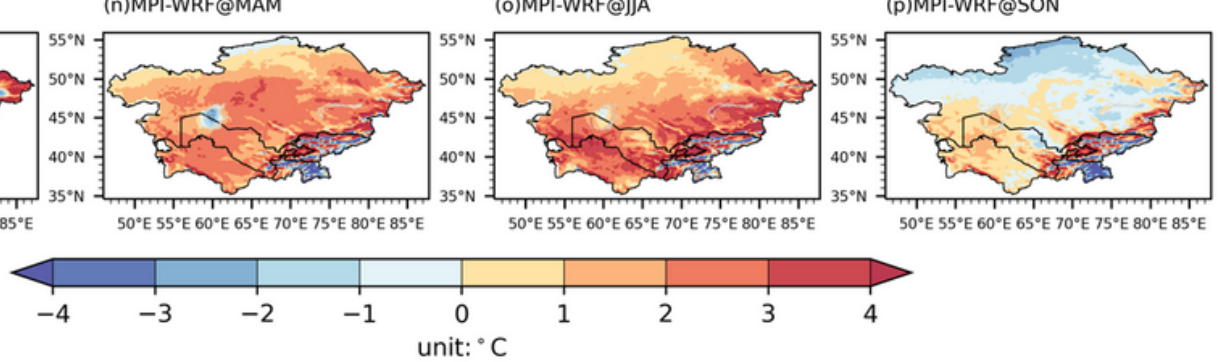

\section{Figure 4}

The observed seasonal Tmean in Central Asia during the reference period (1986-2005, a-d) and the biases in the RCM simulations. DJF: December-January-February, MAM: March-April-May, JJA: June-July-August, SON: September-October-November. Note: The designations employed and the presentation of the material on this map do not imply the expression of any opinion whatsoever on the part of Research Square concerning the legal status of any country, territory, city or area or of its authorities, or concerning the delimitation of its frontiers or boundaries. This map has been provided by the authors. 

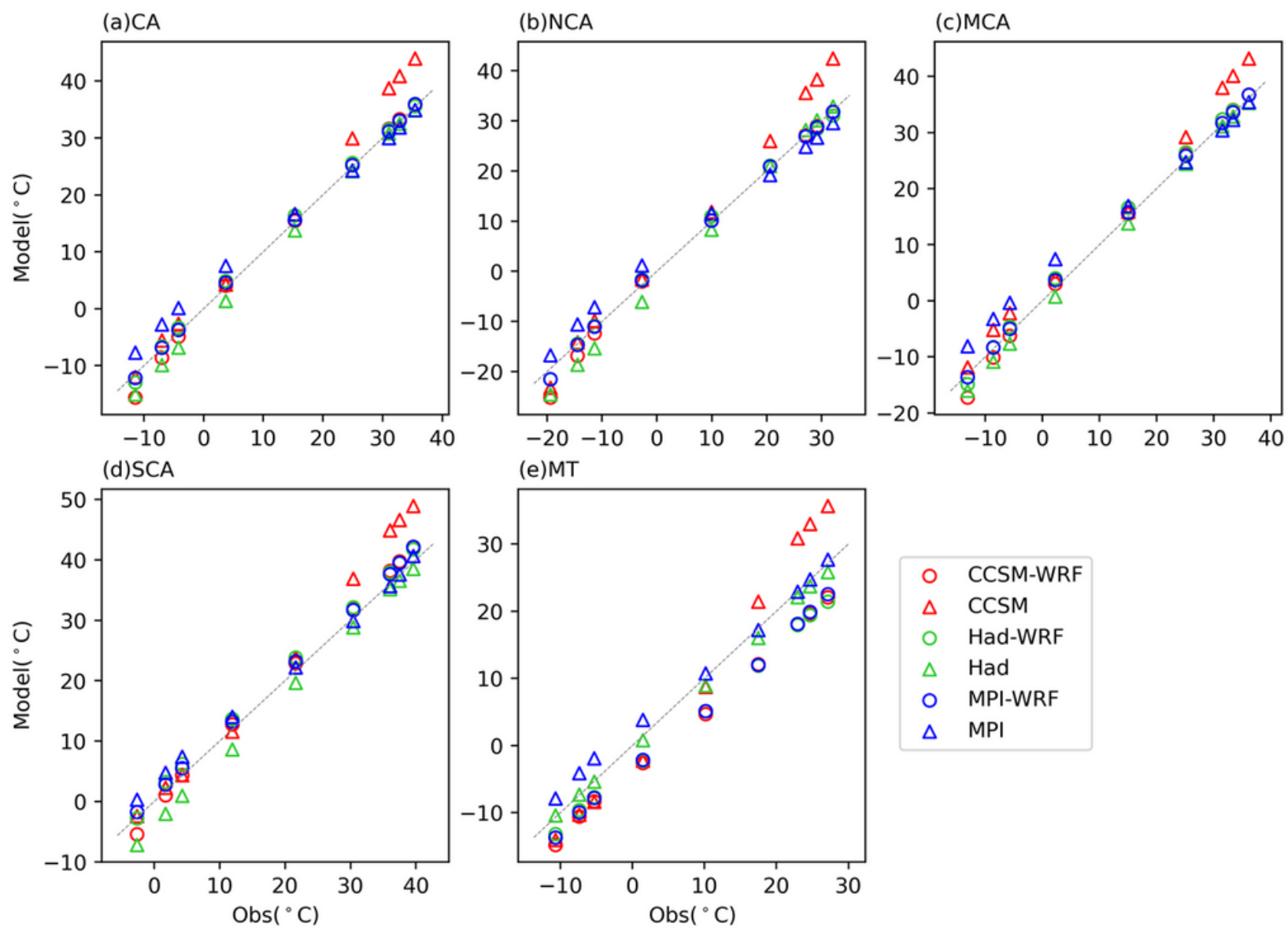

\section{Figure 5}

Comparison of Tmax percentiles (1th, 5th, 10th, 30th, 50th, 70th, 90th, 95th, 99th) from the GCM and RCM simulations against the observations in Central Asia and its climate subregions. Dashed line indicates a perfect description of the percentiles. 

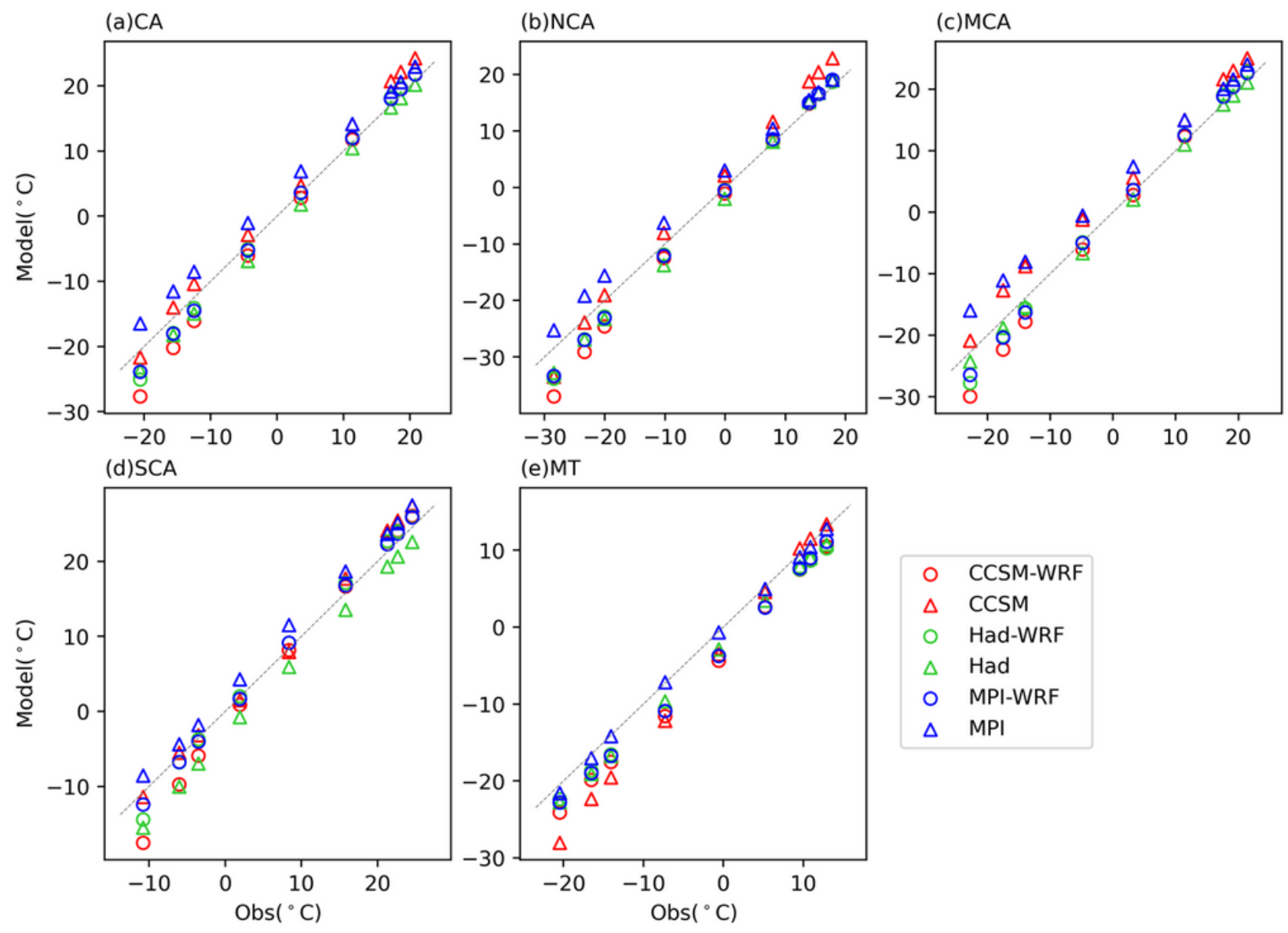

\begin{tabular}{cl}
\hline & CCSM-WRF \\
$\Delta$ & CCSM \\
$\circ$ & Had-WRF \\
$\Delta$ & Had \\
$\circ$ & MPI-WRF \\
$\Delta$ & MPI
\end{tabular}

Figure 6

Same as Fig. 5, but for Tmin. 
(a)ERA5
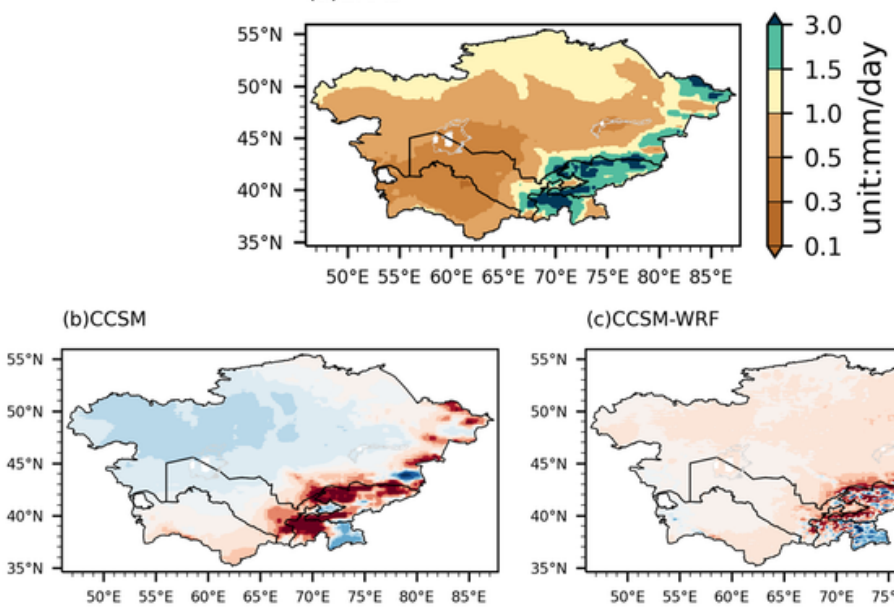

(c)CCSM-WRF
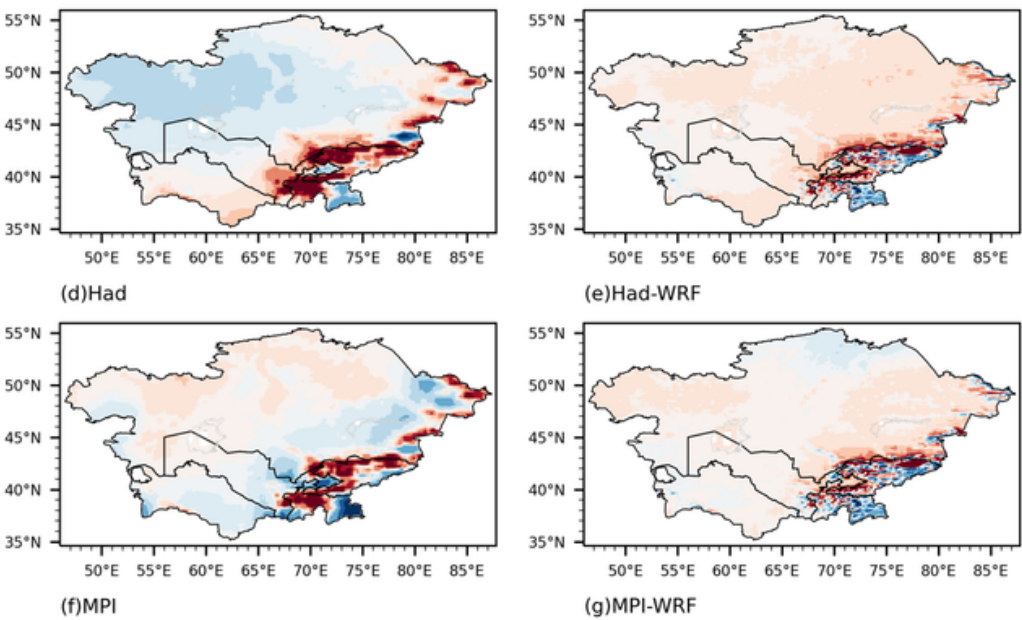

e)Had-WRF

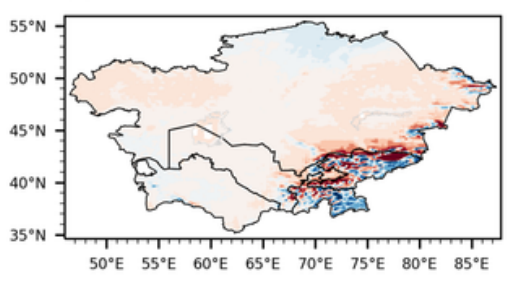

(g)MPI-WRF
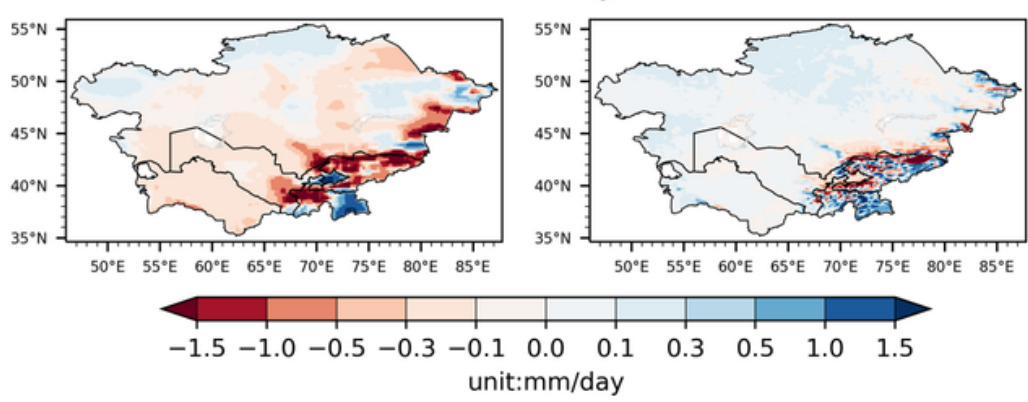

\section{Figure 7}

The observed annual precipitation during the reference period (1986-2005) in Central Asia (a) and the biases in the GCM and RCM simulations (b-g). Note: The designations employed and the presentation of the material on this map do not imply the expression of any opinion whatsoever on the part of Research Square concerning the legal status of any country, territory, city or area or of its authorities, or concerning the delimitation of its frontiers or boundaries. This map has been provided by the authors. 


\section{(a)ANN}
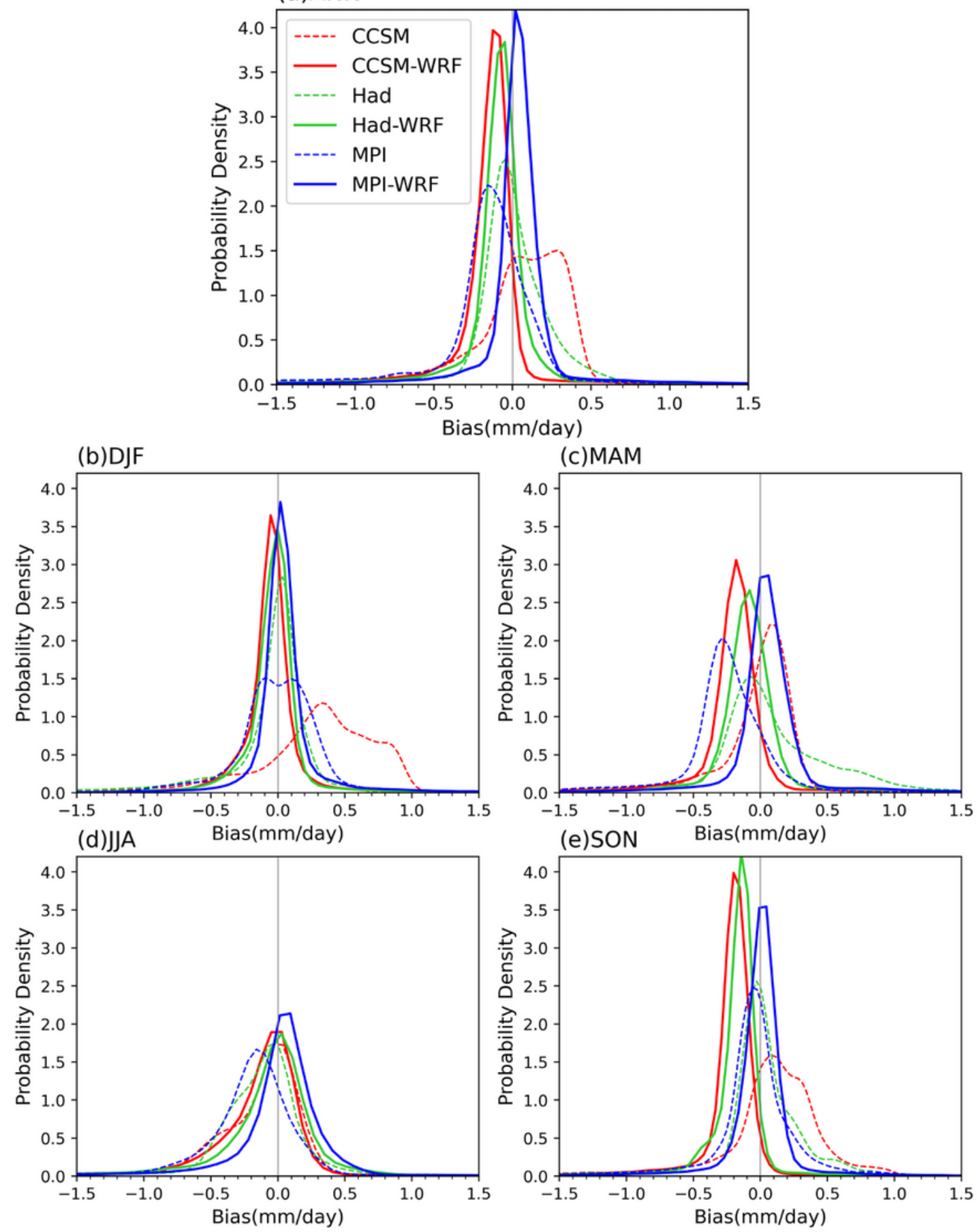

\section{Figure 8}

The Probability Density Functions (PDFs) of the bias in the simulated annual and seasonal precipitation over Central Asia during the reference period (1986-2005). 

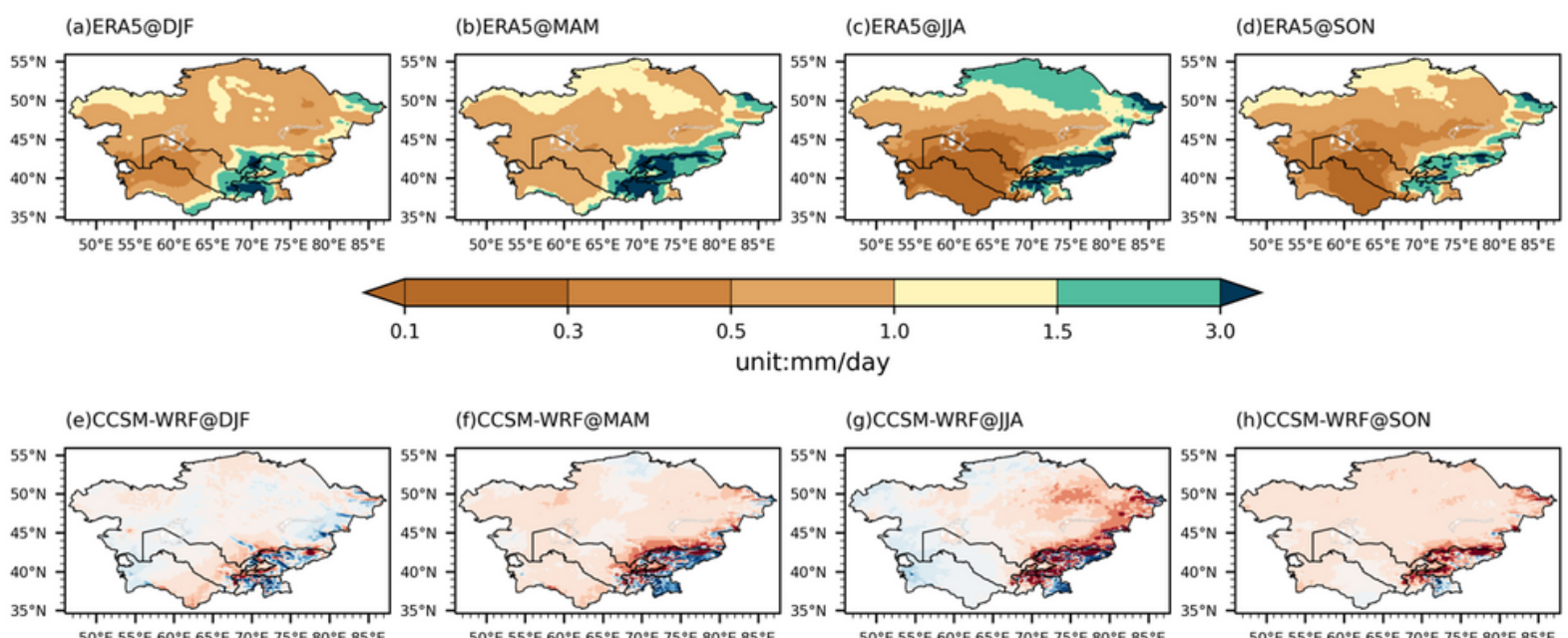

(h)CCSM-WRF@SON

$50^{\circ} \mathrm{E} 55^{\circ} \mathrm{E} 60^{\circ} \mathrm{E} 65^{\circ} \mathrm{E} 70^{\circ} \mathrm{E} 75^{\circ} \mathrm{E} 80^{\circ} \mathrm{E} 85^{\circ} \mathrm{E}$

$50^{\circ} \mathrm{E} 55^{\circ} \mathrm{E} 60^{\circ} \mathrm{E} 65^{\circ} \mathrm{E} 70^{\circ} \mathrm{E} 75^{\circ} \mathrm{E} 80^{\circ} \mathrm{E} 85^{\circ} \mathrm{E}$
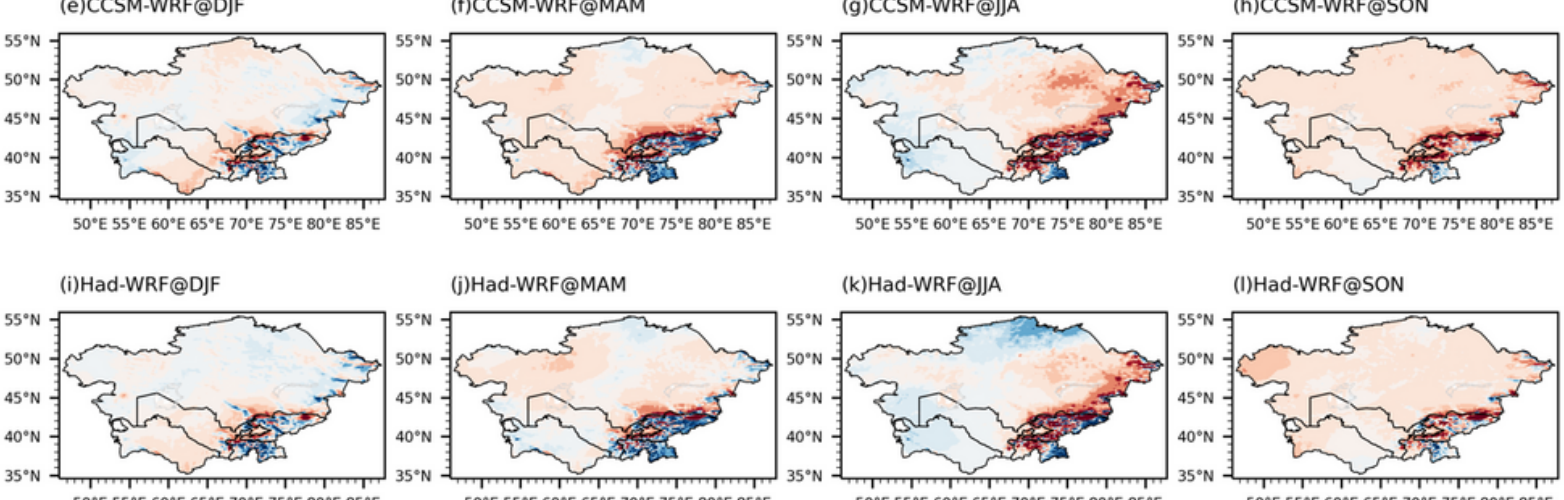

(j)Had-WRF@MAM

(k)Had-WRF@JJA
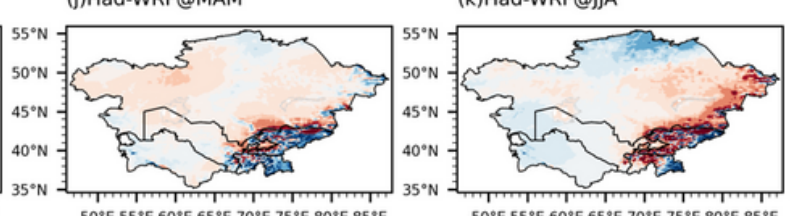

(I)Had-WRF@SON

$50^{\circ} \mathrm{E} 55^{\circ} \mathrm{E} 60^{\circ} \mathrm{E} 65^{\circ} \mathrm{E} 70^{\circ} \mathrm{E} 75^{\circ} \mathrm{E} 80^{\circ} \mathrm{E} 85^{\circ} \mathrm{E}$

(n)MPI-WRF@MAM

(o)MPI-WRF@JJA
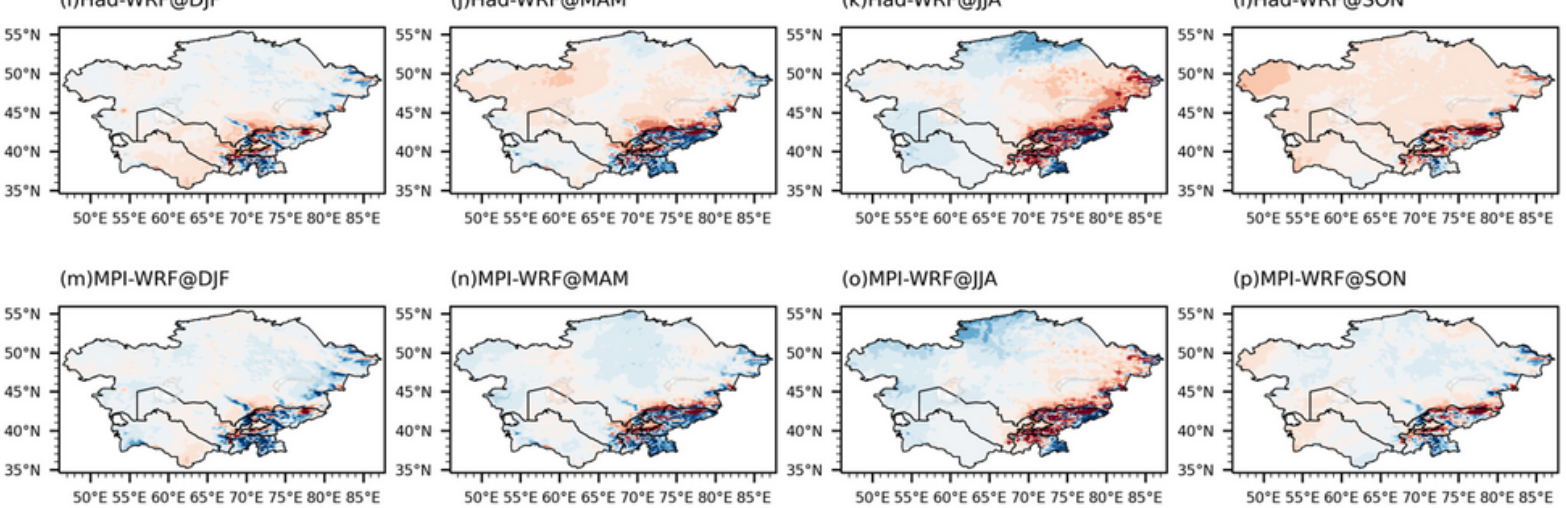

(p)MPI-WRF@SON
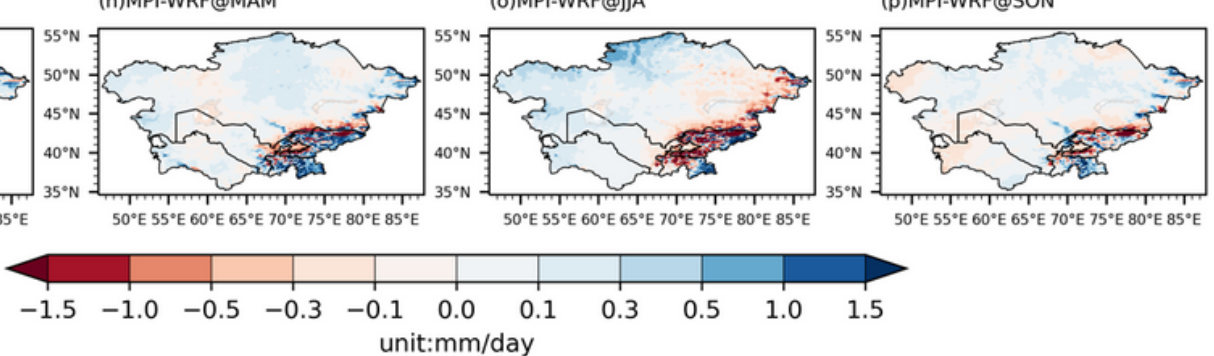

\section{Figure 9}

The observed seasonal precipitation in Central Asia during the reference period (1986-2005) (a-d) and the biases in the RCM simulations (e-p). Note: The designations employed and the presentation of the material on this map do not imply the expression of any opinion whatsoever on the part of Research Square concerning the legal status of any country, territory, city or area or of its authorities, or concerning the delimitation of its frontiers or boundaries. This map has been provided by the authors. 
(a)CA

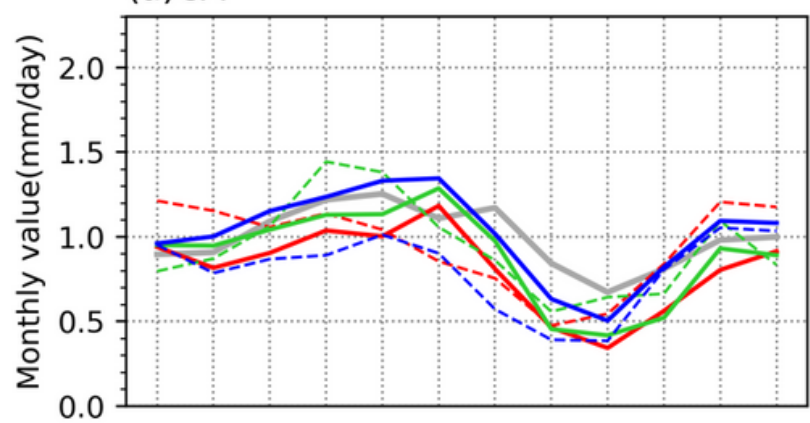

\section{(c)MCA}
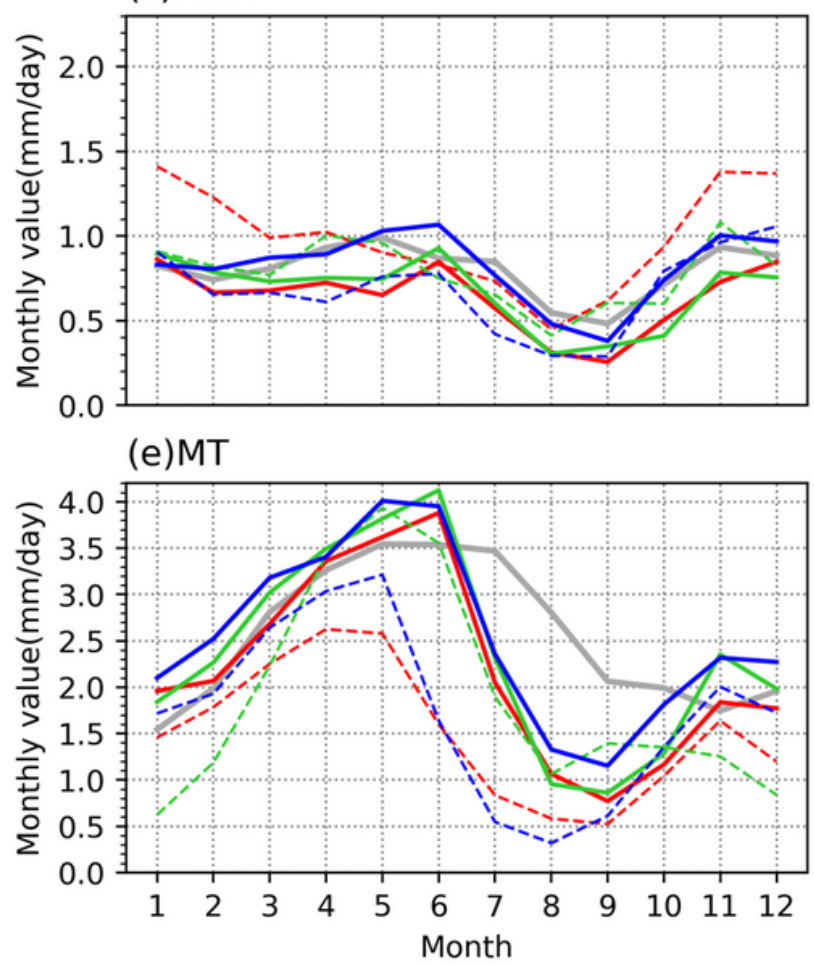

(b)NCA

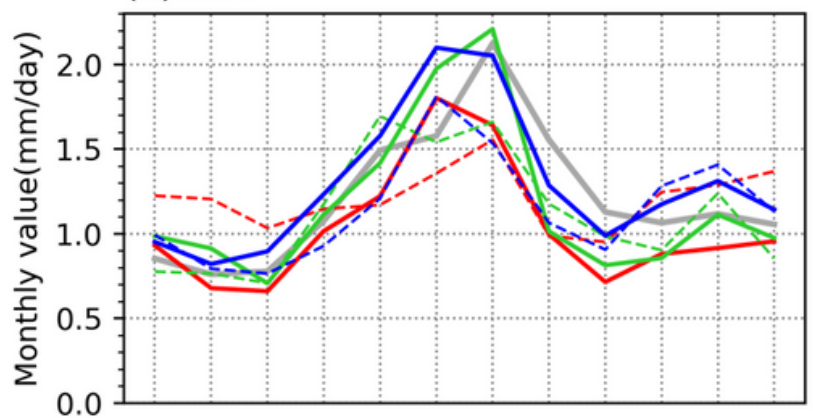

(d)SCA
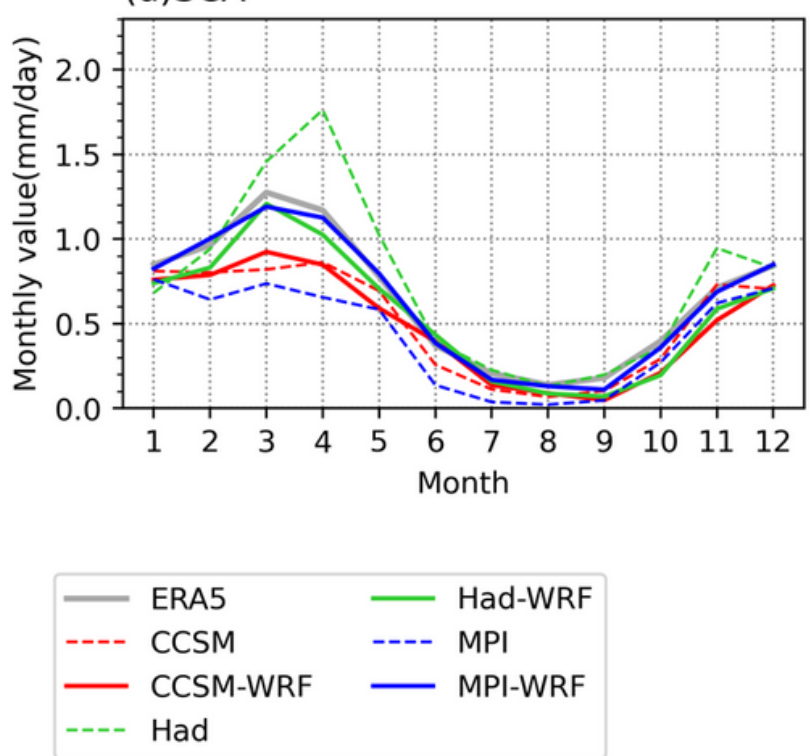

\section{Figure 10}

Mean annual cycle of the monthly precipitation averaged over Central Asia and its climate sub-regions in the observation and model simulations. 

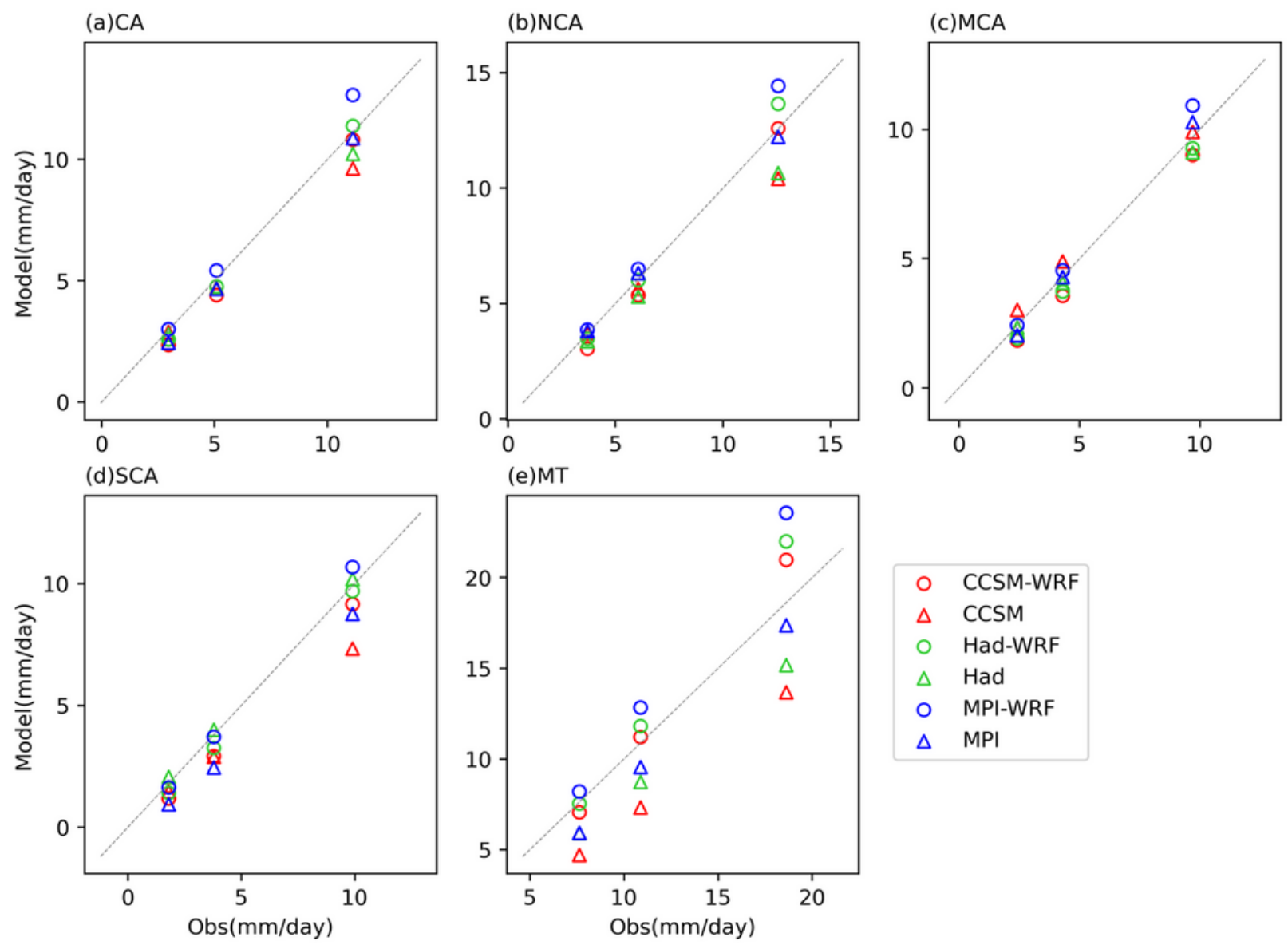

$\begin{array}{cl}\circ & \text { CCSM-WRF } \\ \Delta & \text { CCSM } \\ \circ & \text { Had-WRF } \\ \Delta & \text { Had } \\ \circ & \text { MPI-WRF } \\ \Delta & \text { MPI }\end{array}$

\section{Figure 11}

Comparison of daily precipitation percentiles (90th, 95th, 99th) from the GCM and RCM simulations against the observations in Central Asia and its climate subregions. Dashed line indicates a perfect description of the percentiles. 

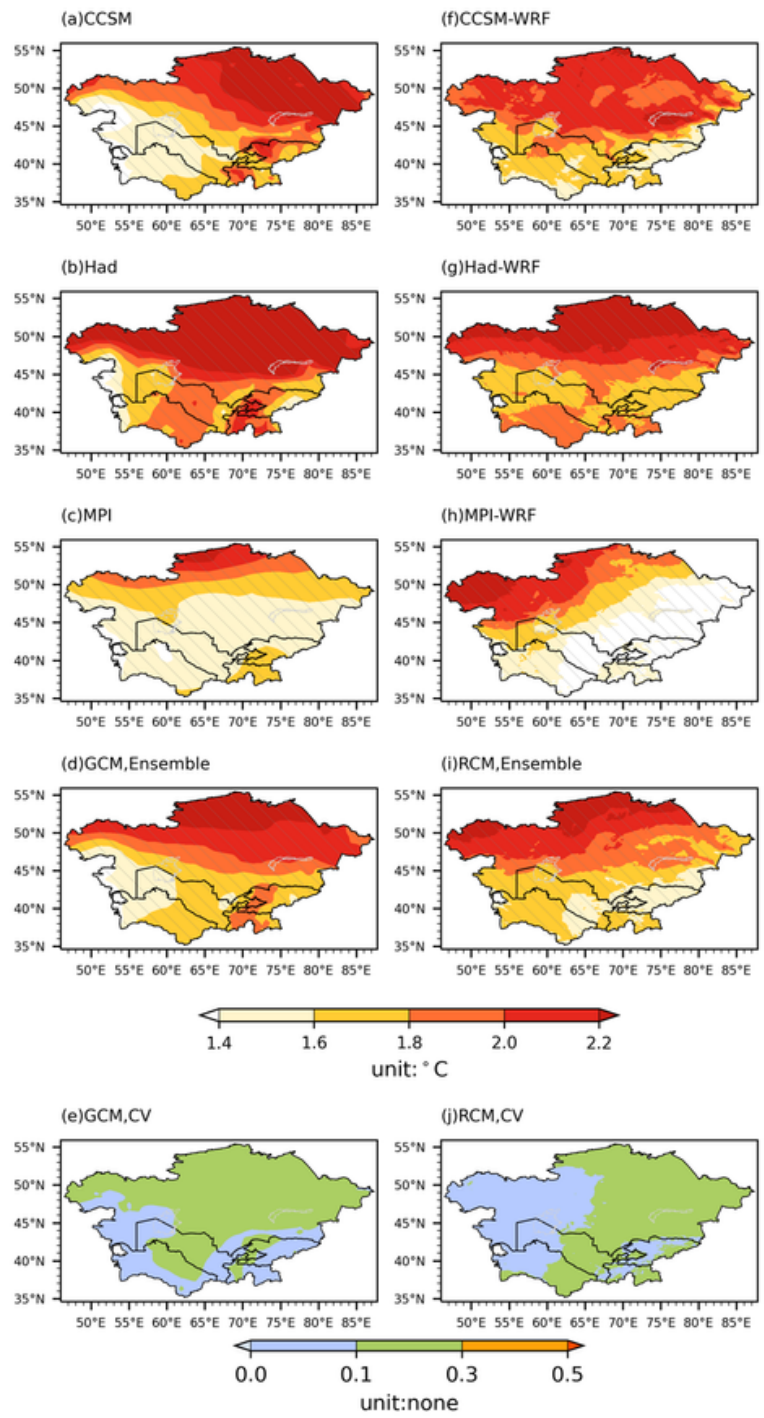

\section{Figure 12}

Projected changes (2031-2050 vs 1986-2005) in annual Tmean over Central Asia in the GCM and RCM simulations $(a-c, f-h)$, and the ensemble means $(d, i)$ and the coefficient of variation $(C V, e, j)$ of the changes. The slashed areas in subplots a-c and f-h indicate where the changes passed the significance test at the $95 \%$ confidence level using the two-tailed Student's t test. The slashed areas in subplot $d$ and $i$ indicate where the signals (+/-) of the changes in the GCM/RCM simulations are consistent. Note: The designations employed and the presentation of the material on this map do not imply the expression of any opinion whatsoever on 
the part of Research Square concerning the legal status of any country, territory, city or area or of its authorities, or concerning the delimitation of its frontiers or boundaries. This map has been provided by the authors.

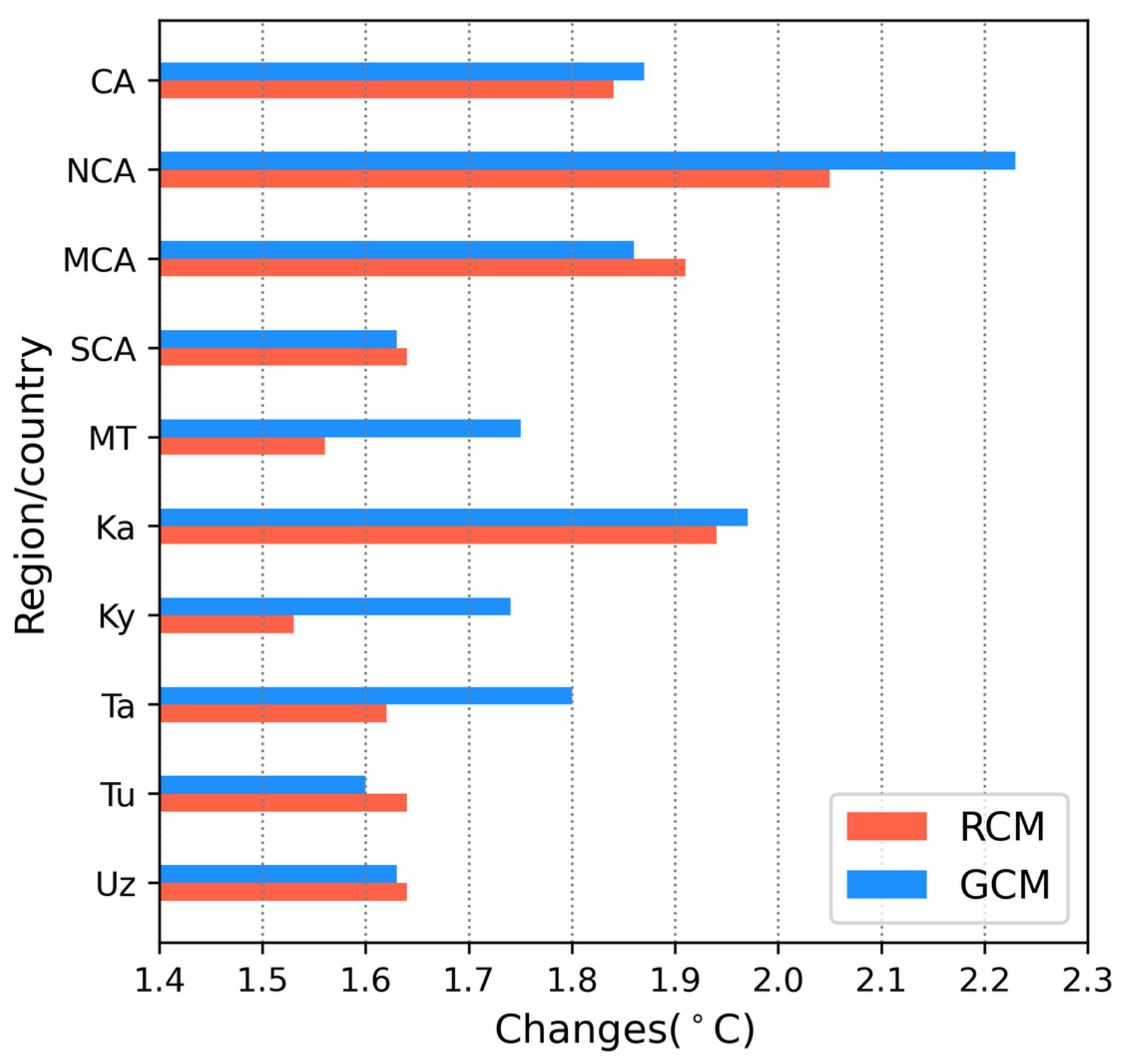

Figure 13

Projected changes (2031-2050 vs 1986-2005) in annual Tmean averaged over Central Asia, its climate subregions, and countries (Ka: Kazakhstan, Ky: Kyrgyzstan, Ta: Tajikistan, Tu: Turkmenistan, and Uz: Uzbekistan) based on the ensemble mean of the GCM and RCM simulations. 

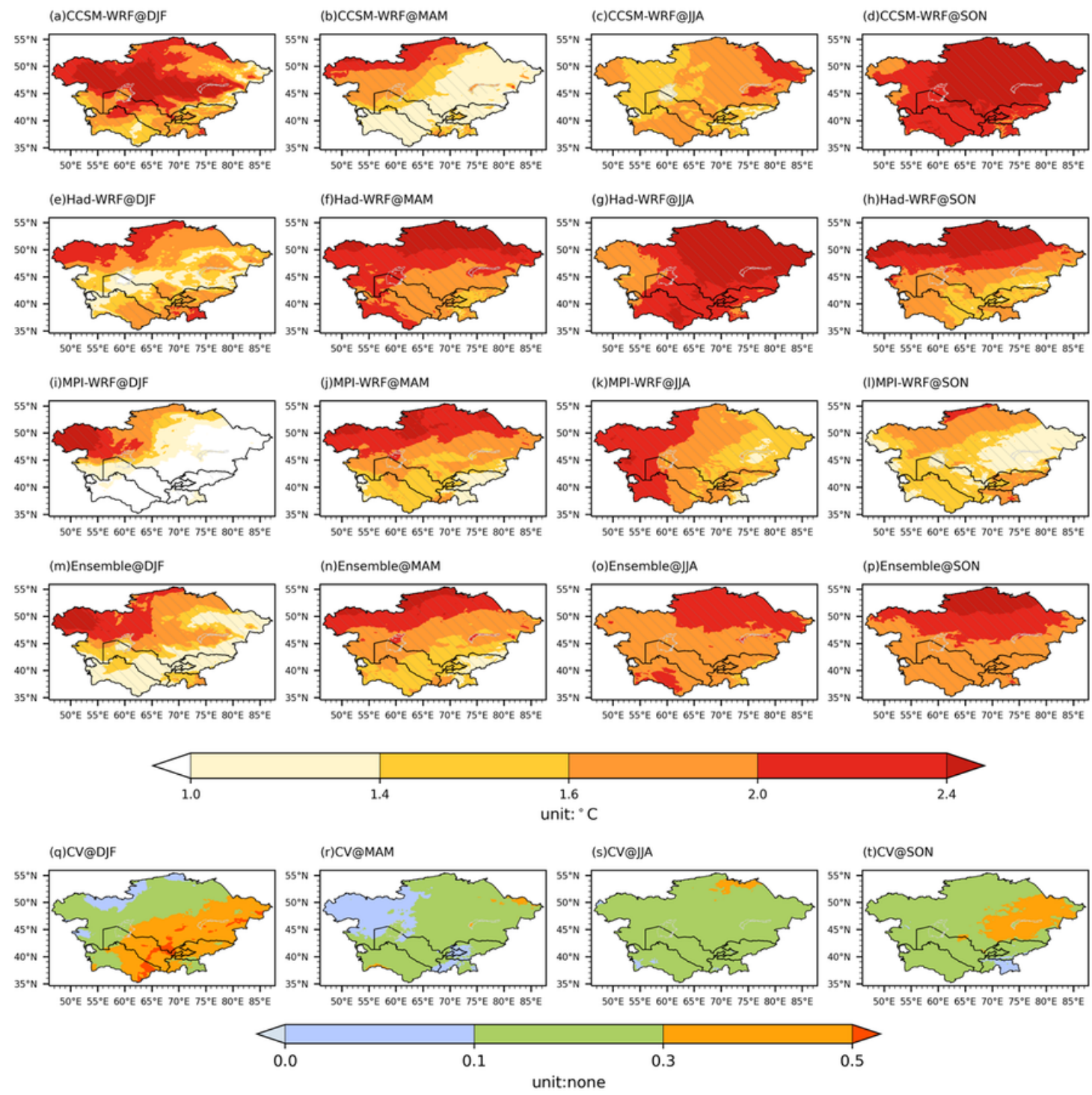

\section{Figure 14}

Projected changes (2031-2050 vs 1986-2005) in seasonal Tmean over Central Asia in the RCM simulations $(\mathrm{a}-\mathrm{l})$, and the ensemble means $(\mathrm{m}-\mathrm{p})$ and the coefficient of variation (CV, q-t) of the changes. The slashed areas in subplots a-l indicate where the changes passed the significance test at the $95 \%$ confidence level using the two-tailed Student's $t$ test. The slashed areas in subplot m-p indicate where the signals (+/-) of the changes in the RCM simulations are consistent. Note: The designations employed and the presentation of the material on this map do not imply the expression of any opinion whatsoever on the part of Research Square 
concerning the legal status of any country, territory, city or area or of its authorities, or concerning the delimitation of its frontiers or boundaries. This map has been provided by the authors.

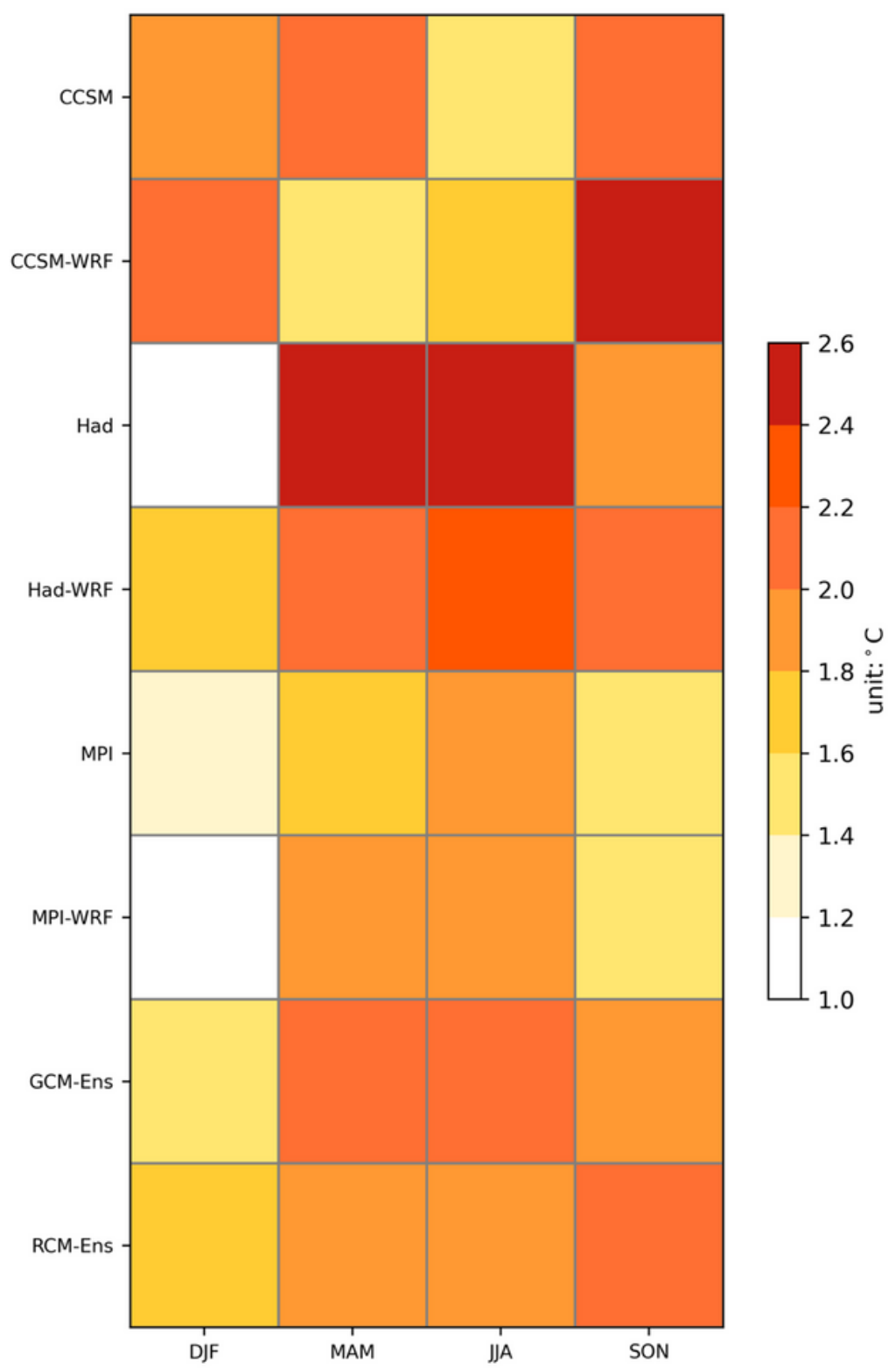

\section{Figure 15}

Projected changes (2031-2050 vs 1986-2005) in seasonal Tmean averaged over CA in the GCM and RCM simulations and their ensemble means. 

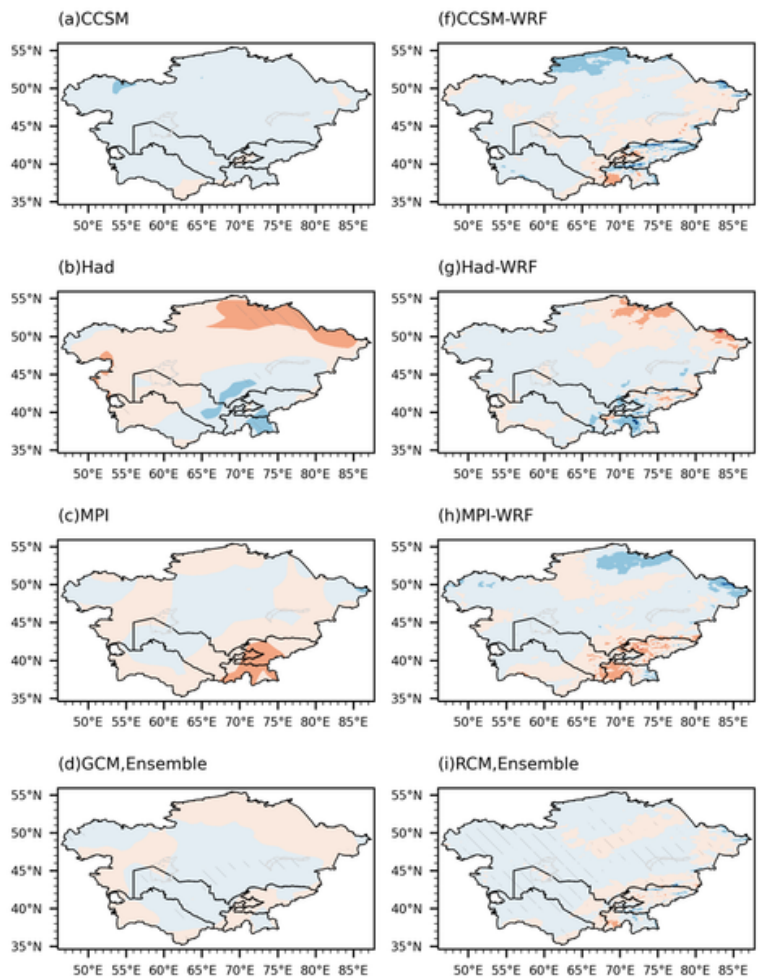

$$
\begin{array}{ccccccc}
-0.5 & -0.3 & -0.1 & 0.0 & 0.1 & 0.3 & 0.5 \\
& & & \text { unit:mm/day }
\end{array}
$$

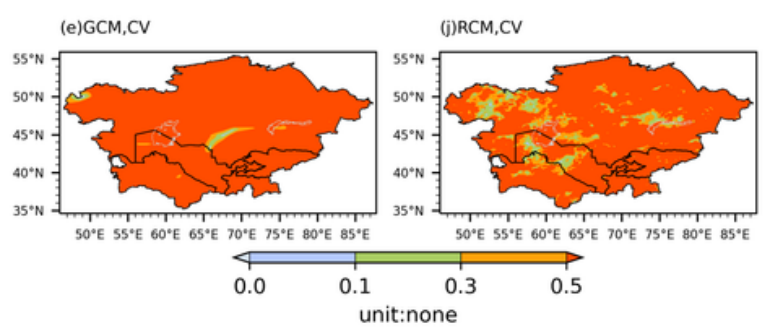

\section{Figure 16}

Same as Fig. 12, but for annual precipitation. Note: The designations employed and the presentation of the material on this map do not imply the expression of any opinion whatsoever on the part of Research Square concerning the legal status of any country, territory, city or area or of its authorities, or concerning the delimitation of its frontiers or boundaries. This map has been provided by the authors. 

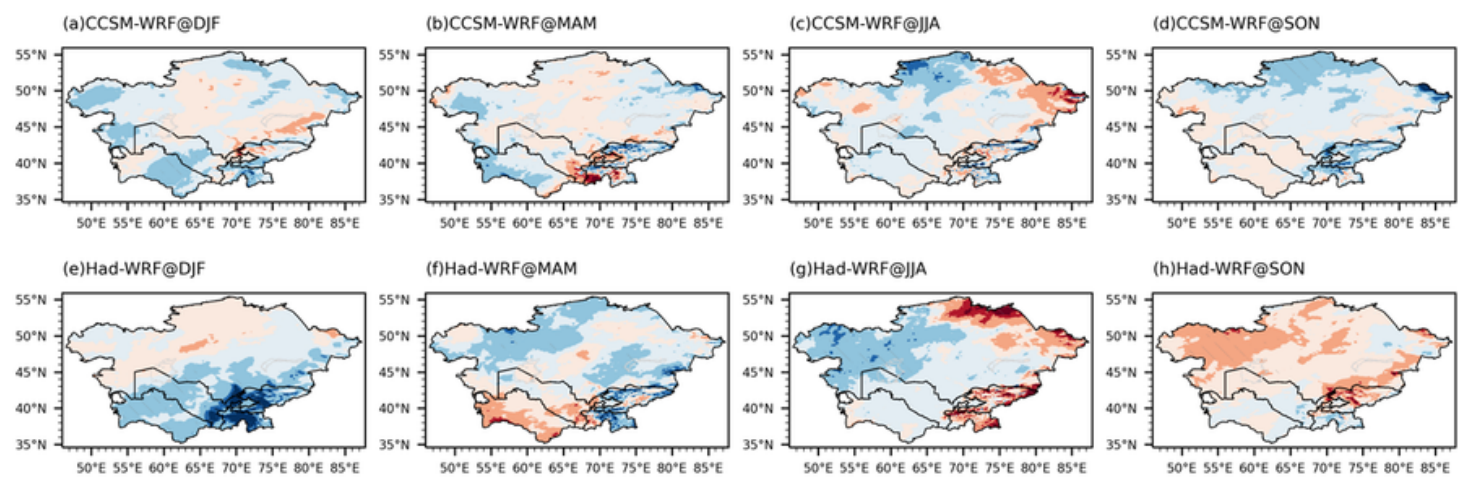

(g)Had-WRF@JJA

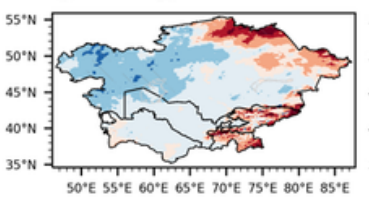

(h)Had-WRF@SON
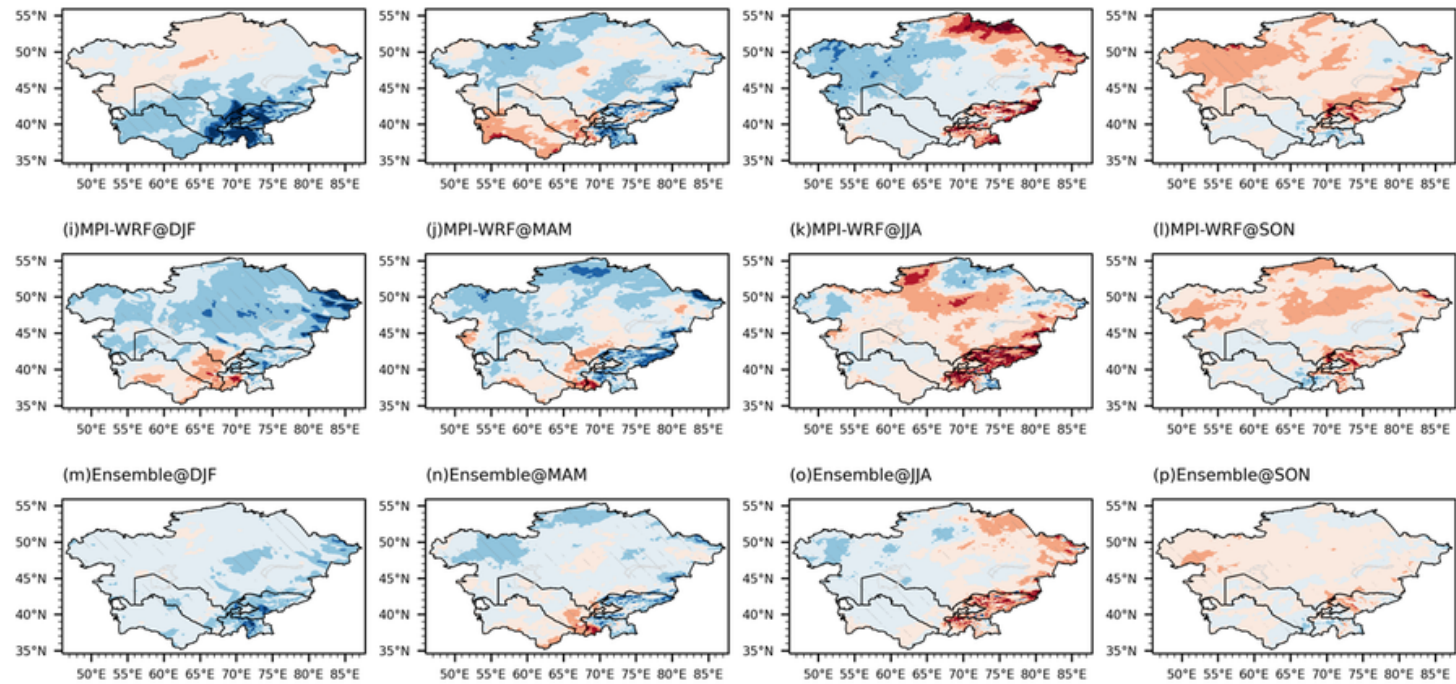

(o)Ensemble@JjA
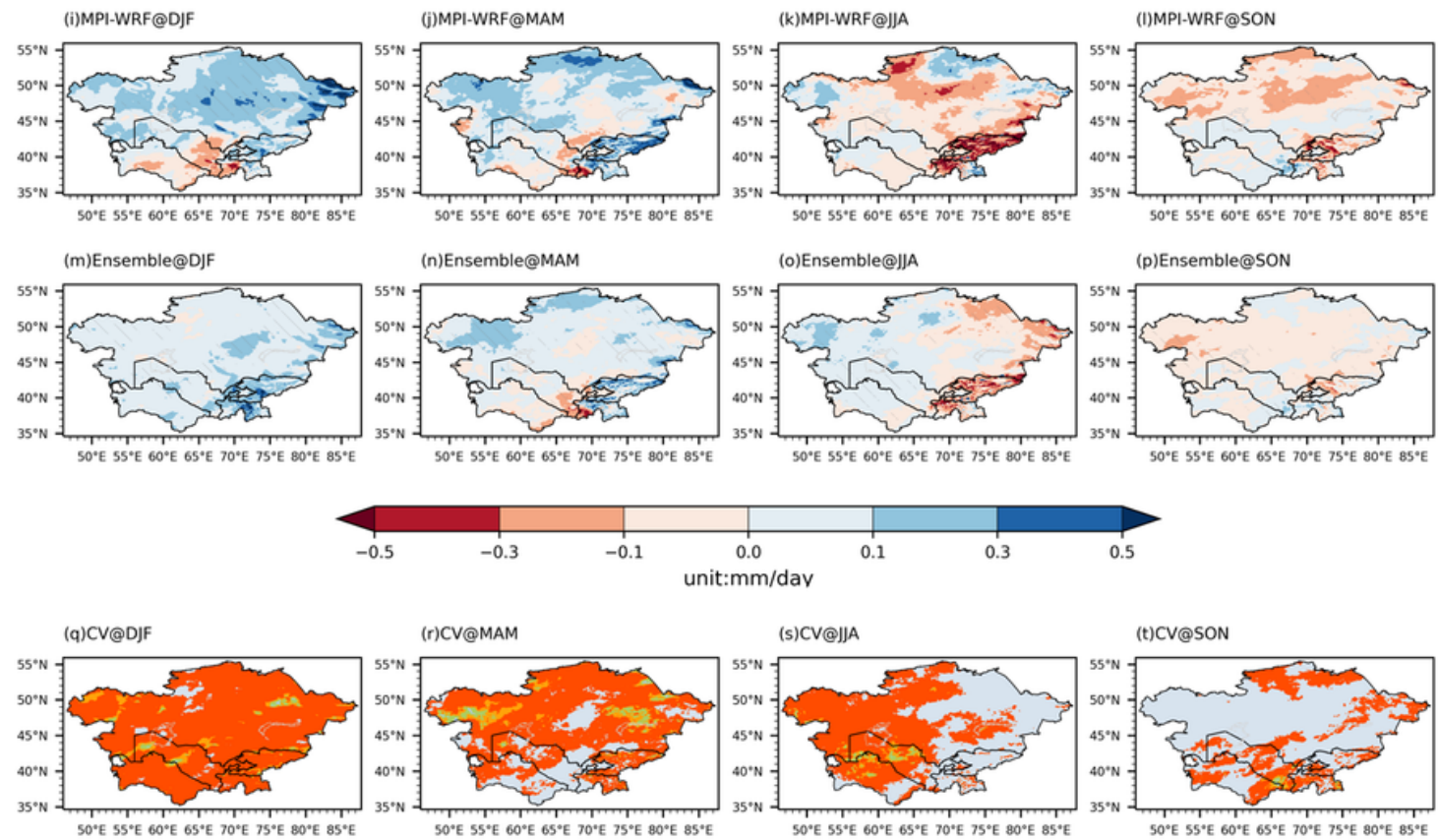

(s)CV@JJA
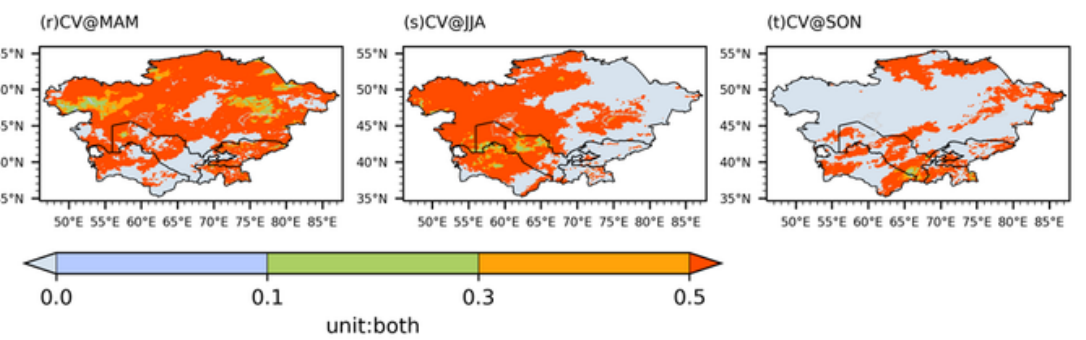

\section{Figure 17}

Same as Fig. 14, but for seasonal precipitation. Note: The designations employed and the presentation of the material on this map do not imply the expression of any opinion whatsoever on the part of Research Square concerning the legal status of any country, territory, city or area or of its authorities, or concerning the delimitation of its frontiers or boundaries. This map has been provided by the authors.

\section{Supplementary Files}


This is a list of supplementary files associated with this preprint. Click to download.

- CAsupportinginfo.pdf 